\title{
La guerra de Successió en el teatre i la poesia catalans de l'època
}

\author{
F. Xavier Vall i Solaz \\ Universitat Autònoma de Barcelona. Departament de Filologia Catalana \\ francesc.vall@uab.cat
}

Rebut: desembre de 2014

Acceptat: juny de 2015

\section{Resum}

Tot i la significació de la guerra de Successió als Països Catalans i l'abundant bibliografia sobre l'esdeveniment i les seves recreacions literàries posteriors, la literatura catalana d'aquest període no ha estat encara prou estudiada, malgrat algunes estimables aportacions. Com que mancava una aproximació de conjunt actualitzada, aquest article procura oferir un panorama, complex i amb noves dades, d'obres literàries catalanes escrites pels volts del conflicte i que s'hi refereixen, centrat sobretot en la poesia, però aporta també notícies del teatre. S'analitzen els textos relacionant-los amb les tendències literàries (especialment, el Barroc i els models populars) i la conjuntura històrica. Es tenen en compte els bàndols borbònic i austriacista, procurant donar una visió matisada de diferents actituds, que, a vegades, evolucionen. La mitificació té com a contrapunt la crítica burlesca o desolada.

Paraules clau: segle XVIII; guerra de Successió; Barroc; classicisme; literatura catalana; teatre; poesia; literatura popular; propaganda; sàtira.

Resumen. La guerra de Sucesión en el teatro y la poesía catalanes de la época

A pesar de la significación de la guerra de Sucesión en los Países Catalanes y la abundante bibliografía sobre el evento y sus recreaciones literarias posteriores, la literatura catalana de este período no ha sido aún suficientemente estudiada, si bien se cuenta con algunas estimables aportaciones. Como faltaba una aproximación de conjunto actualizada, este artículo procura ofrecer un panorama complejo y con nuevos datos, de obras literarias catalanas escritas alrededor del conflicto y referidas a él, centrado sobre todo en la poesía, pero aportando también noticias del teatro. Se analizan los textos relacionándolos con las tendencias literarias (especialmente, el Barroco y los modelos populares) y la coyuntura histórica. Se tienen en cuenta los bandos borbónico y austracista, procurando dar una visión matizada de diferentes actitudes, que a veces evolucionan. La mitificación tiene como contrapunto la crítica burlesca o desolada.

Palabras clave: siglo XvIII; guerra de Sucesión; Barroco; clasicismo; literatura catalana; teatro; poesía; literatura popular; propaganda; sátira.

Abstract. The War of the Spanish Succession in Catalan Contemporary Theatre and Poetry of the Time

In contrast to the significance of the War of Succession in the Catalan Countries and the vast publications on the event and its later literary recreations, the Catalan literature of the period has not yet been widely studied, despite some estimable contributions. Due to the lack of an updated and 
comprehensive approach, this article aims to provide a complex overview with new data on Catalan literary works written around the conflict and referring to it. Although the main focus is on poetry, news of theatre is also provided. The texts are analyzed according to literary trends (especially the Baroque and popular models) and the historical juncture. The Bourbon and Austrian factions are taken into account in an attempt to give a nuanced view of different attitudes, which sometimes evolve. Mythification has its counterpoint in mocking or devastating criticism.

Keywords: Eighteenth century; War of Spanish Succession; Baroque; classicism; Catalan literature; theatre; poetry; popular literature; propaganda; satire.

\title{
Sumari
}

\author{
1. Introducció 4. Conclusió \\ 2. El teatre Referències bibliogràfiques
}

3. La poesia

\section{Introducció}

Encara que el segle XVIII ha estat anomenat «de les Llums», sols ho va ser parcialment. ${ }^{1}$ D'altra banda, a l'estat espanyol les concepcions il-lustrades es van introduir tard i poc plenament, de manera que va persistir força el Barroc, amb diferents graus d'evolució, tot i que no hi manquen tampoc, a més de patrons populars, aspectes relacionables amb el classicisme, el rococó, el neoclassicisme, la Il-lustració i el romanticisme. Els quatre darrers moviments, però, segons la cronologia més restrictiva, són posteriors a la guerra de Successió i, en cas de qualificar una obra de «classicista», caldria precisar en quin sentit i, en especial, si s'ajusta als models del Grand Siècle. ${ }^{2}$

Òbviament, en aquest conflicte internacional, present en altres literatures, van coincidir les cultures dels diversos països participants. Convindria estudiar més, però, fins a quin punt, a pesar de les dificultats de la guerra i l'elitisme d'algunes

1. Aquest article és producte de l'encàrrec d'un panorama literari per a l'exposició «Biblioteques UAB a l'entorn del 1714»<http://pagines.uab.cat/biblioteques1714/content/literatura> (2014) i s'inscriu en el projecte FFI2011-25051. Com que, feliçment, comença a abundar la bibliografia sobre la literatura catalana de l'edat moderna, em limitaré a citar la més específica. Regularitzo els textos antics, amb criteris que no crec rellevant detallar. A vegades, existeixen diverses edicions o impressions de les obres, particularment dels fullets, però només n'indico l'exemplar quan ho crec necessari.

2. Segons el Dietari d'un adroguer, ficció d'Oriol Garcia Quera (2013: 81), el 31 de juliol de 1706 s'hauria representat una traducció castellana de Le malade imaginaire (1673), de Molière, a la Casa de les Comèdies de Barcelona. Tenim molt poca informació, però, sobre aquest teatre en els anys de la contesa, en què va servir de magatzem de palla durant el setge (Carrera, 1951, II: 413-414; Alier, 1990: 47). La invenció de l'escenificació potser s'inspira en la que es va realitzar a Maó, ja durant el domini francès (Vila, 1992), mentre que la recepció de Molière s'ha documentat tardanament (Fontcuberta, 2005). 
manifestacions, es van relacionar. El llatí continuava essent una opció literària (Coroleu, 2006; Coroleu i Paredes, 2010 i 2014ab) i els austriacistes feien servir força el castellà, per bé que sense caure en la dura repressió borbònica del català.

Cal destacar que va contribuir a un notable auge cultural el fet que l'arxiduc Carles, a més de visitar altres ciutats, establís la cort a Barcelona des de 1705 fins a esdevenir emperador, el 1711, i que hi restés un parell d'anys més Elisabet Cristina, amb qui s'havia casat el 1708. En canvi, les estades de Felip V a Catalunya, entre les quals destaca la del 24 de setembre de 1701 al 8 d'abril de 1702, en què va efectuar el jurament reial i se'n va solemnitzar el casament amb Maria Lluïsa de Savoia, van ser més esporàdiques. Durant les distintes etapes de la conflagració i encara posteriorment, va proliferar l'exaltació austriacista o borbònica, la qual va prendre sovint formes literàries. No obstant això, diverses obres transcendeixen el proselitisme a fi d'oferir una visió més complexa de les circumstàncies, manifestant, a vegades, malestar. Seria simplista classificar taxativament els escriptors en «aguilots» $\mathrm{i}$ «botiflers», perquè a vegades canvien de partit $\mathrm{i}$ adopten aquestes posicions amb diversos matisos.

Contrastant amb el tòpic de la Decadència, el progrés dels estudis ha evidenciat ja la considerable vitalitat del català, no sols col-loquialment, i que tant la quantitat com la qualitat de la literatura catalana moderna superen exigües expectatives, si bé encara s'hauria d'indagar i analitzar més la incidència literària de la guerra de Successió arreu dels Països Catalans. Ens circumscriurem al teatre i la poesia, deixant de banda l'abundant prosa, que, a més de diversos estudis i edicions, disposa ja de panorames i és el centre d'atenció d'un panorama sobre tota la literatura de l'època (González, 2013). Evidentment, el caràcter general d'aquest article i l'extensió no permeten una anàlisi detallada de les obres esmentades, que exposaré tendint a l'ordenació cronològica.

\section{El teatre}

Moltes celebracions, com s'ha estudiat força, incorporaven multitud d'espectacles, entre els quals representacions que a vegades prenien un caràcter considerablement teatral. Així, el 3 de maig de 1701 un carro triomfal es convertia, reiteradament, en un cadafal per escenificar, amb diverses tramoies, les lloances de les nimfes de Tortosa i dels continents al personatge de Felip V, que n'agraïa «los afectos siempre amantes». ${ }^{3}$ Similarment, la nit del 12 de novembre es va representar, davant del balcó del palau virregnal barceloní on eren aquest monarca i la seva muller, una peça epitalàmica escrita i interpretada per alumnes de retòrica de la Universitat Literària de Barcelona: Josep de Vertamon Fises i de Rull (Júpiter), Francesc Arcidet i Pintor (Cupido), Baltasar de Bastero i Lledó

3. Alborozos festivos, leales obsequiosas demostraciones con que la fidelísima y ejemplar ciudad de Tortosa celebró el feliz arribo a su corte de nuestro monarca y señor D. Felipe de Borbón, Barcelona: Rafael Figueró, s. a.: 45-56, Querol (2001: 302-303) i Montagut (2004). Pel que fa a l'impressor, vegeu Camprubí (2010 i 2013) i, quant a l'estada del monarca a Catalunya: Revilla (1983), Riera Fortiana (1989 i 1993), Pérez Samper (1989 i 2000) i Cuesta (2009). 
(Venus), Josep Campllonch i Bosch (Apol-lo), Raimon Llaurador i Vilana Perlas (Juno), Joan Mitjà i Domingo (Mart), Joan Marmer i Mora (Minerva), Francesc Gible i de Viladomar (Mercuri) i Francisco Aguirre i Oms (Diana). ${ }^{4}$

S'ha suggerit que el 1703 es va conspirar ja a favor de l'austriacisme representant a la torre de Bellesguard, propietat de Joan de Gualbes, una Loa, d'Antoni Peguera i Aimeric, per a la Comedia de los juegos olímpicos, d'Agustín de Salazar Torres, i un Poema armónico, del mateix autor que la lloa, d'Antoni de Clariana i Gualbes i de Joan Antoni de Boixadors, comte de Savellà. ${ }^{5}$ L'establiment de Carles III a Barcelona va suposar un estímul cultural important, particularment per a la promoció de l'òpera i va atraure-hi els escenògrafs Galli Bibiena, ${ }^{6}$ per bé que la cort de Felip V també fomentava el teatre i, específicament, el de caràcter musical. ${ }^{7}$

Maria Teresa Pérez Picazo (1966: 297 i 342) esmenta com a peça la Mueca de mojigangas y mojigangos,$^{8}$ merament per les referències a aquest gènere, present també en una narració criticant l'adhesió de Pere II de Portugal a l'arxiduc Carles des de 1703, després d'abandonar el bàndol borbònic: Mojiganga de mojigangas, papelón de papelones, manifiesto de manifiestos, reflexión de reflexiones, cuento de cuentos. ${ }^{9}$ A la mateixa qüestió es refereix la Loa nueva: A más tinieblas más luces (s. d.; Pérez Picazo, 1966: 341). Degué ser escrita per a la Segunda jornada de la zarzuela de Hacer cuenta sin la huéspeda con loa y matachines nuevos (s. d.). ${ }^{10}$ Es va editar també una Comedia famosa del recibi-

4. Es descriu la celebració i es reprodueixen sengles versions de l'obra a Devotos obsequiosos cultos y leales festivas aclamaciones con que celebró la excelentísima ciudad de Barcelona la gloriosa translación de Olaguer, su santo, y la regia venida de su católico monarca, Felipe IV en Aragón y $V$ en Castilla, conde de Barcelona, y su feliz consorcio con... María Luisa, princesa de Saboya, s. d.: 170-189 i Festivas demonstraciones y majestuosos obsequios con que el muy ilustre y fidelísimo consistorio de los deputados y oidores del Principado de Cataluña celebró la dicha que llegó a lograr con el deseado arribo y feliz himeneo de sus católicos reyes D. Felipe IV de Aragón y V de Castilla, conde Barcelona..., y María Luisa, Barcelona: Rafael Figueró, 1702: 162-179. Es coneixen diverses dades sobre aquests, aleshores, estudiants. Evidentment, també s'utilitzaven escenaris fixos, a vegades creats per a l'ocasió (vegeu, per exemple, Palmada i Vila, 2013: 443-443).

5. Porta (1984: 163-164), Serra (1984), Brown (1989a i 1989-1990 —en què s'ocupa de poesies atribuïdes a Peguera, entre les quals un sonet de Lope-, 2008 i 2011-2012[2015]), Albareda (1993: 117), Campabadal (2006: 52-56 i 2007) i Galindo López i Medarde (2014). Clariana ja havia adreçat un emblema a Felip V considerat provocatiu (Revilla, 1983: 399-400). Dos fills de Boixadors, Bernat Antoni i Joan Tomàs, es dedicaran també a la poesia (Campabadal, 2003-2004: II, 32-36). Ja em referiré a Gualbes.

6. Ribera (1985 i 1987), Bravo (1986), Alier (1990), Casademunt (2001), Sommer-Mathis (2007), Bonastre (2009), Bernardini (2009), Cortès (2009), Garcia Espuche (2009a), Massip (2012), Socias (2013), Miralpeix (2014: 64-71) i Pérez Treviño (2014).

7. Vegeu, per exemple: Morales (2000), López Alemany i Varey (2006), Lolo (2009) i Fernández (2012).

8. Barcelona: Rafael Figueró, 1707, i Rubió (1985-1986: III, 190 i 257).

9. Llibre publicat, fingidament, a Lisboa a costa del rei portuguès, «que es quien lo ha de pagar todo», s. a. Vegeu també Rubió (1985-1986: III, 257).

10. Hacer cuenta sin la huéspeda: Zarzuela que se representa actualmente en Villa-Viciosa de Portugal, recreo del rey don Pedro s'havia publicat a Saragossa el 1704, sense peu editorial, i se n'ha conservat algun entremès o sainet. 
miento que le hizo el rey don Pedro de Portugal al archiduque Carlos, en què el monarca portuguès se sent enganyat per l'arxiduc. ${ }^{11}$

Amb llicència donada a Madrid el 1706, es va publicar Quien bien tiene y mal escoge: Coloquio en la sublevación de Barcelona y Valencia: Dirigido en elogio del rey nuestro señor don Felipe $V$, en què, d'acord amb la continuació del refrany del títol («del mal que le venga no se enoje»), el «gracioso» Mortero acaba imaginant que l'arxiduc fuig «por estos cerros / de Monjuí», perquè arriba el duc d'Anjou «con todo el estruendo / marcial del poder del mundo, / cortando, a diestro, y siniestro, / piernas, brazos y cabezas / de pícaros Malcontentos». ${ }^{12}$ En canvi, en «Nueva comedia que se representa en el teatro de Europa», text esquemàtic, però que no sembla un esbós, s'imaginen tres jornades en què el duc d'Anjou aniria, respectivament, de París a Madrid, d'aquesta ciutat a Barcelona i d'aquí a Itàlia, una «tramoia y apariencias» d'anglesos i holandesos, una lloa en la qual intervenen «todos los gavachos y los que sin ser franceses lo son», un entremès a càrrec d' «un cardenal [Portocarrero]», un ball per a «la reina niña» (com era coneguda la jove esposa de Felip V) i una apoteòsica muixeranga formada per Lluís XIV, que faria riure tothom. ${ }^{13}$

Com que el derrotat va ser Felip V, i tan estrepitosament que va haver de refugiar-se al domini francès i tornar a la península per Navarra, s'hi complau la Comedia famosa del sitio de Barcelona y fuga del duque de Anjou, signada «Joseph Ribes». ${ }^{14}$ Sobre l'autoria, Francesc Foguet (2015: 7-8), a més de referir-se a la proposta de François Suréda que ja comentaré, apunta:

Malgrat totes les recerques fetes, encara no tenim cap certesa sobre l'autor de Comedia famosa del sitio de Barcelona... Una altra hipòtesi plausible de formular, que Ribes fos un notari o un jurista afincat a la capital catalana, queda, almenys de moment, sense poder-se confirmar documentalment. Car han estat infructuoses les nostres consultes del fitxer manual de Josep M. Madurell i Marimon a l'Arxiu Històric de Protocols de Barcelona, que, com és sabut, recull documentació parcial de capítols, testaments i inventaris relativa a nobles, ciutadans honrats, juristes, arquitectes, doctors, mercaders i altres oficis dels segles XV-XVIII, i també de l'inventari de l'esmentat arxiu corresponents als segles XVII i XVIII ». [...] Pel seu domini dels recursos literaris, fins al punt que es permet refistolaments culteranis-

11. Barcelona: Francisco Guasch, s. a. A la Biblioteca Nacional de España, n'hi un exemplar publicat a Lisboa, s. n., i, a la de la Universidade de Coimbra, un altre amb peu de Sevilla: Pedro Joseph Díaz, ambdós amb data de 1704.

12. S. d.: 8. N'existeix una edició de Sevilla, per Juan de la Puerta, i una altra de Granada, per la Imprenta Real de Francisco Ochoa, a costa de Nicolás Prieto, ambdues s. a. Vegeu també Pérez Picazo (1966: 345) i Alabrús (2001: 184-185).

13. BC (Biblioteca de Catalunya), ms. 3613: f. 106. Per a la descripció dels manuscrits, vegeu Duran (2011)

14. L'obra es menciona en diversos estudis. Pel que fa a les edicions, vegeu Suréda (2004: 402), Centre de Documentació i Museu de les Arts Escèniques de l'Institut del Teatre (2014) i Foguet (2015: 9-10), que ressenya les que li serveixen de base per a la seva. Abunden diversos escrits sobre el setge coetanis o no gaire posteriors. Feliu de la Peña (1709: III, 549) explica, probablement al-ludint a alguna representació teatral, que Carles III va celebrar algunes victòries al seu palau «con suntuoso festín y comedia». 
tes pujats de to (sobretot en els discursos reials), tot fa pensar que devia ser un professional de les lletres (no necessàriament de primera fila). I és molt probable que fos un autor afí al poder, potser vinculat i tot a la cort, potser un militar (si fem cas del coneixement que demostra i l'atenció que presta als fets bèl-lics) que es disposaria a fornir, a través del gènere dramàtic, d'argumentari oficial a la publicística austriacista, molt marcada pel triomfalisme durant els anys 1705-1706 (cf. Alabrús, 2001: 173-183). A més d'editar-la en la impremta «oficial» de Barcelona, poc després del setge, la comèdia ofereix una visió partidista i bel-ligerant del conflicte, molt atenta a delimitar els episodis històrics i les figures més rellevants del théâtre de guerre.

Al corral de l'Olivera de València, des del 22 de setembre de 1706, vuit dies abans de l'entrada de l'arxiduc a la ciutat, fins al 21 de gener de l'any següent, es va representar, amb gran èxit, una obra teatral sobre el setge barceloní (Suréda, 2002, 2004: 305-324, 389-424 i 482). El filipista Josep Vicent Ortí, en el seu Diario, s'hi refereix com una «comedia», «escrita por el licenciado Fábregues, natural de la ciudad de Orihuela y habitador de la de Valencia, cuyo asumpto era el suceso de Barcelona». ${ }^{15}$ Una «redondilla» que va copiar de «los papeles impresos que fijaron en las esquinas» precisa que es tracta del setge:

$$
\begin{aligned}
& \text { Hoy de Carlos se blasona } \\
& \text { el valor, siendo testigo } \\
& \text { la fuga de su enemigo } \\
& \text { y sitio de Barcelona. }
\end{aligned}
$$

El Contrallibre major (Zabala, 1966: 165, 173-178 i 192; Suréda, 2004: 396), que anomena l'obra «comedia del Sit de Barcelona», qualifica l'autor d' «un ingeni de València». La crònica Sucesos fatales de estat ciudad y reino de Valencia, del borbònic Isidro Planes, descriu, burlescament, l'obra com un «comedión» «del sitio de Barcelona, desemparado por Felipe V, y gloriosa defensa, publicándola por milagrosa» i, a fi de criticar el fanatisme austriacista, especifica que «hubo quien quiso matar a una comedianta que hizo el papel de Felipe $\mathrm{V}$ ». ${ }^{16}$

Suréda conjectura que podria tractar-se de la mateixa obra editada a Barcelona, hipòtesi que, a més, reforçarien les referències del text als valencians, tot i que s'expliquen també per la intensificació de les relacions entre Catalunya i València (Pérez Aparicio, 2012), i l'estada a Barcelona, almenys el 26 de febrer de 1706, de la companyia que la va representar, la valenciana d'Antonio Lorriaga i Juana Ondarro. A més, cal remarcar que els versets publicitaris coincideixen força amb el títol de l'edició barcelonina, la qual encaixa també amb la descripció de Planes per les referències a la naturalesa miraculosa de la victòria i la caracterització del duc d'Anjou, encara que són tòpiques.

15. Aldana (1958: 47), Suréda (2002: 30 i 2004: 396), Escartí (2007: 170) i Pérez Aparicio (2008: II, 509-510). No es pot assegurar el sentit precís amb què s'usa el terme licenciado.

16. Escartí (2007: 170) i Pérez Aparicio (2008: 510). Suréda utilitza aquesta font, però no la cita en relació amb aquesta comèdia. 
Suréda suggereix que «Joseph Ribes» podria ser un pseudònim adoptat per l'esmentat Fàbregues, tement la victòria filipista, si bé conjectura que potser només va adaptar l'obra. De totes maneres, no tothom s'amagava. ${ }^{17}$ D'altra banda, es tracta d'una combinació de nom i cognom molt corrent. Per exemple, es documenten diversos «Josep Ribas» — l'ortografia no n'és sempre rellevanten el setge de Barcelona: un capità i un auxiliar, fill seu, i un negociant (Garcia Espuche, 2014: 407-408, 420, 497 i 696-700).

Francesc de Castellví (1997-2002: III, 64 i 393) es refereix, com a informador seu, a Josep Ribas, natural d'Oriola —igual que l'autor proposat per Ortí-, que va ser secretari (no precisa quan) del comte de la Puebla, Antonio de Portugal, el «comandante de las tropas españolas del rey Carlos». ${ }^{18}$ Un «Joseph Ribas y Fábregas» figura, entre els eclesiàstics, en una «relación de los valencianos que dejaron el Reino de Valencia para seguir al rey Carlos III» (Feliu de la Peña, 1709: III, 629; Erill, 2014: 125). A més de la correspondència del segon cognom amb l'esmentat per Ortí, en el manuscrit del seu Diario (conservat a la Biblioteca de la Universitat de València), la línia anterior a la que comença amb «Fábregues» no es justifica, a diferència de la resta, com si s'hagués deixat deliberadament un espai en blanc per afegir algun mot (potser el nom i el primer cognom). ${ }^{19}$

Virginia León (2007a: 248; 2007b: 214) esmenta un «Josep Ribes i Fabregat» que, segons «sembla», «va mantindre contactes amb l'historiador Castellví i li proporcionà informació sobre els successos de València per a les seves Narraciones históricas». Ha tingut l'amabilitat d'indicar-me les dades que n'ha aplegat:

Se trata de un sacerdote, natural de Orihuela, beneficiado de la iglesia de Almusafes y de la iglesia de San Martín de Valencia. Estuvo refugiado en Cataluña antes de 1709 y fue secretario del conde de la Puebla, comisario general de las tropas españolas del rey Carlos. Exiliado en Viena, mantuvo contactos con el historiador Castellví, proporcionándole información sobre los sucesos de Valencia. En 1725 estaba en Nápoles, de oficial de la Secretaría de Estado y Guerra del Reino de Nápoles. ${ }^{20}$

17. Les lletres de «Ribes» s'inclouen en «Fàbregues», exceptuant la «i», però no en sembla un anagrama. Tampoc cal pensar que fos un nom clandestí.

18. En Castellví (1997-2002: II, 243 i 203), entre altres referències a aquest comte, s'esmenta en una llista dels que es van passar al bàndol de Carles III en entrar a Castella i el van seguir a València i indica que, atès que, «desde Valencia pasaba a mandar» les fronteres d'Aragó, el 24 d'octubre de 1706 va ser rebut per la noblesa aragonesa. Castellví (1997-2002: I, 518) i Porta (1984: 304-305) mencionen també un Josep Ribas que el 15 d'agost de 1705 havia estat cridat al vaixell Devonshire, ancorat prop de Dènia i Alacant, juntament amb Domènec Perera i Francesc Matalonga, per Georg von Hessen-Darmstadt, després que aquest manés escriure nombroses cartes a la recerca de suports, i l'endemà va desembarcar a Calella per repartir-ne diverses, una a Francesc Saleta. De totes maneres, aquests fets, narrats amb altres detalls en Feliu de la Peña (1709: III, 530), segons la fe d'errates d'aquest llibre, s'haurien d'atribuir a «Juan Ribas».

19. Es remarca amb punts suspensius entre claudàtors en la transcripció d'Escartí (2007: 170).

20. Segons m'ha precisat, es basa en els llibres de Castellví i de Feliu de la Penya esmentats — com hem vist, però, en el d'aquest, el segon cognom és «Fàbregas», en lloc de «Fabregat», formes que, a part de l'accentuació, sols difereixen en la darrera lletra—, en el manuscrit «Relación de los valencianos que dejaron su patria por seguir a Carlos III», de Manuel Fuster i Membrado, i 
Evidentment, aquestes coincidències es poden combinar en conjuntures no prou provades, però raonables: per exemple, que la Comedia famosa del sitio de Barcelona y fuga del duque de Anjou fos obra de Josep Ribes i Fàbregues o Fabregat, d'Oriola, al qual es podrien atribuir altres dades aportades, si la identificació ha estat sempre correcta.

El 31 d'octubre de 1706, amb motiu de l'entrada a Mallorca de l'esmentat Joan Antoni de Boixadors com a virrei, els col-legis de notaris i d'escrivans hi van representar al Born la Coronación de nuestro católico monarca Carlos III: Celebrada en Viena (1707), en què se'n recrea l'entronització, després de demanar l'emperador el suport als electors i als ambaixadors. ${ }^{21}$ També el 1707 es va publicar El embuste sin verdad y la verdad sin embuste, martillo de pertinaces y alientos de firmes: Comedia famosa en que se representa al vivo lo sucedido en España desde la muerte de Carlos II... hasta la deseada entrada de nuestro enamoradísimo monarca Carlos III... en este catalónico Principado. ${ }^{22}$ Com és freqüent, hi intervenen distingits personatges: l'arxiduc Carles, el duc d'Anjou, l'emperador Leopold, Lluís XIV, el cardenal Portocarrero... El mateix any figura editada a Madrid, «a costa de la compañia de butifleres de esta corte», por Antonio Bizarrón o Vizarrón (segons la impressió), editor de la Gaceta de Madrid i de pamflets filipistes, el burlesc Teatro de culpa y pena en juicio particular de la monarquía de España: Dedicado al excelentísimo señor monsieur Francisco Ronquillo, corregidor, coronel, general, gabinete y más gabinete y presidente de Castilla, obra que, signada pels «ingenios de monsieur don Fernando Matanza y monsieur don conde de Ibangrande», ridiculitza els temors a les atrocitats dels austriacistes (Pérez Picazo, 1966: 343; Alcoberro, 2007b: 192-193). Aquests, però, van fracassar en l'intent de recuperar Madrid i, perduda la batalla d'Almansa (1707), van anar cedint diverses ciutats de València, Aragó i el Principat. «Quan el mal ve d'Almansa / a tots alcança», va esdevenir un adagi popular (Blasco, 1985: 161), que titula un disc del grup Al Tall.

M. T. Pérez Picazo (1966: 297 i 336) menciona algunes de les abundants obres en «forma dialogada», entre les quals Dialogo entre un soldado catalán y un castellano sobre la defensa de Barcelona en el asedio del año de 1713.23 Té caràcter relativament més teatral, remarcat per les acotacions, un col-loqui també austriacista, La más heroica defensa, igualment entre un soldat català, que empra només la seva llengua en un monòleg i una cançó, i un de castellà, que canvia de bàndol gràcies a la intervenció de la Justicia i la Verdad. ${ }^{24}$ La rica tradició allegòrica, fomentada pels actes sacramentals, va mantenir una considerable presència en el teatre polític. En el Diálogo y disputa jocosa que tuvieron un francés y un castellano en el campo de Barcelona en tiempo de levantar el sitio las tro-

les dades que li va facilitar José Luis Cervera Torrejón. En una llista de 1734, consta «Joseph de Ribas» com a oficial de la Secretaria de Guerra de Nàpols cessant (Alcoberro, 2002: II, 248).

21. Palma: Estampa de Miguel Cerdá y Antic, 1707; Garcías (1998: 31-33, 2003 i 2005: 47-55).

22. Girona: Franciso Oliva, 1707, i Pérez Picazo (1966: 337).

23. S. d., Rubió (1985-1986: III, 184), Gilard (2000: 320, 335-336 i 382), Alabrús (2001: 284-285) i

Gifre (2013: 54).

24. Barcelona: Francisco Guasch: 1713, i Escobedo (2009: 68). 
pas a Francia a mes de marzo de 1714, els interlocutors es critiquen mútuament, alhora que elogien «la invencible Catalunya». ${ }^{25}$

Malgrat la censura teatral borbònica, encara aflora el record de la guerra en la Gran comedia: El crisol de la fineza y fundación mercenaria, signada «Francisco Rossell y Oriol». ${ }^{26}$ Igual que no manquen al-lusions al poder en la rica tradició de col-loquis o raonaments valencians, al Principat es critica Felip V en el Coloquio que pasó (no se sabe si por alto) entre Pedro Bexiga y Belisa Mondongo sobre las fiestas hechas en Barcelona los dias 9, 10 y 11 deste año de 1746 a la proclamación del señor don Fernando VI. ${ }^{27}$ Durant el regnat d'aquest, amb data de 1755, se satiritzarà també el sistema borbònic en Lo batlle $i$ cort del borboll - $\mathrm{O}$ dels borbolls - (Sala, 2007; Villalonga, 2009), ${ }^{28}$ semblantment a un entremès mallorquí titulat del batle (Serrà, 1987: 179), i en altres peces (Brown, 1988). En canvi, a Menorca, sota el domini britànic consagrat pel Tractat d'Utrecht (1713), la literatura catalana i, en particular, el teatre es beneficiaven del revifament econòmic, de la permissivitat envers la llengua catalana i d'una bona recepció de la Il·lustració i el neoclassicisme.

\section{La poesia}

També aquest gènere era un potent instrument propagandístic, sobretot mitjançant fulls volanders. ${ }^{29}$ Algunes cançons s'acompanyaven de música, que no sempre s'ha conservat. ${ }^{30}$

\subsection{Precedents}

Francesc Vicent Garcia, el primer recull imprès de l'obra del qual es va editar el 1703, havia vaticinat que guiarien, «per nostra campanya, / les banderes reals d'Espanya / armades esquadres», versos que van ser considerats una predicció de la molt posterior guerra dels Segadors en la introducció de La famosa comedia de la entrada des marqués de los Vélez en Cataluña (1641) (Rossich, 2010: 507). S'ha adjudicat a l'escriptor més destacat de l'època d'aquella contesa, Francesc Fontanella, una dècima de 1700 en la qual es retreia que Felip V només era duc d'Anjou, però se n'ha refutat l'atribució (Rossich, 2001; Valsalobre, 2015). Entre altres arguments, no sols contrastaria amb la circumstància que Fontanella es va

25. Barcelona: Francisco Guasch, s. a.: f. [2r], i Gilard (2000: 336 i 379).

26. Barcelona: Pablo Campins, aprovada el 1742, i Alabrús (2001: 391-392).

27. Barcelona: Josep Giralt, s a., i Alabrús (2001: 389).

28. A més dels significats comuns del terme borboll i del seu ús en al·lusió als Borbons, convé tenir present que s'anomenava així la Sala de Plets (actualment del Tinell) del Palau Reial Major.

29. Pérez Picazo (1966), Comas (1985), Ibáñez (1982 i 1983), Núñez (1988), Alabrús (1991, 1996 i 2001), Brown i Melchor (1995), Escobedo (1995, 1996 i 2009), Gilard (2000 i 2005), Rodríguez-Sánchez (2000), Borreguero (2003), Mora (2012), Gifre (2013) i Vela (2014ab), a més de les estimables aportacions de les històries de la literatura, particularment Rubió (1985-1986) i Comas (1981), i referències en estudis històrics.

30. Torrente (2007), Ayats (2009), Escobedo i Rossell (2013) i J. Pujol (2014). 
haver de refugiar al Rosselló a l'empara de la monarquia francesa, sinó que ho impedeix la data autèntica de defunció, delimitada ja per Anna M. Torrent ([1967]: 5-7 i 1968: 7).

\subsection{El conflicte successori i la revolta}

Amb motiu de la mort de Carles II, es van publicar unes Lágrimas amantes, compilades per Josep Rocabertí, professor de retòrica al col·legi jesuític de Cordelles, i unes Nenias reales y lágrimas obsequiosas, promogudes per l'Acadèmia dels Desconfiats, ambdós llibres amb alguns poemes en català. ${ }^{31}$ La successió va fer témer ja una situació catastròfica, com il·lustren diverses poesies del ms. 2000/1 de la Biblioteca de Catalunya atribuïdes a Joan de Gualbes (Brown i Melchor, 1995: 54-55, 81-107; Baró, 2009: 298), qüestionablement (Rossich i Valsalobre, 2006: 363-364 i 370):

La mort de Carlos me dóna
moltas cosas que pensar:
y·a nous borbolls veix entrar
a ma pàtria Barcelona;
lo que més pena me dóna
en mig de tan cruel fat
és vèurer falta[r] ll[e]altat
en alguns dels catalans:
y si·no ajudan los san[t]s
ne temo gran disbarat.
Celebre vuy lo burboll
dels jutjes lo disbarat:
més celebra la ciutat
vèurer nostre bisbe foll;
lo diputat és cap mo[1],
lo governador xixell,
fa tot quant vol lo Concell;
fan festas, van als banquets,
ixen uns torts, altres drets
y tots se'n van al bordel[1]. ${ }^{32}$

Com que, en ocasió de l'estada de Felip V a Barcelona, el 2 d'octubre de 1701 es va ordenar que els gremis ornessin els principals paratges per on havia de passar el rei, els mercaders de llenços van guarnir la porta de la Boqueria amb una construcció en què van penjar sis quadres relatius a episodis històrics que simbolitzaven la fidelitat dels catalans, explicats en sengles quartetes en català

31. Barcelona: Juan Pablo Martí, 1701, i Barcelona: Rafael Figueró, 1701, respectivament. Vegeu també Rubió (1985-1986: III, 22-23), Comas (1981: 15-16, 550-553 i 645-649), Campabadal (2003-2004: II, 27-29) i Rossich i Valsalobre (2006: 361-362).

32. Brown i Melchor (1995: 88). 
escrites en targes: Fiveller xuclant les nafres enverinades de Ferran d'Antequera - en lloc de reclamant-li el vectigal—, la davallada al purgatori de Ramon de Perellós a la recerca de Joan I, el traç de les quatre barres amb la sang de Guifré el Pilós per Carles el Calb, la donació de les portes de Nàpols per Alfons el Magnànim a Barcelona en agraïment de la participació en la conquesta (segons diverses fonts, es van cremar en un incendi de 1757), Joan Blanques sacrificant el seu fill a fi de no lliurar Perpinyà i el rescat de l'honor de l'emperadriu d'Alemanya per Ramon Berenguer III. ${ }^{33}$ Entremig, hi havia sis targes més, guarnides amb fullatges verds i daurats, també amb sengles quartetes catalanes, en la segona de les quals s'advertia:

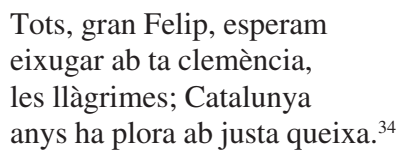

Si bé aquest rei va ser elogiat (García Cárcel, 2002), el malestar va anar aflorant (Alabrús, 2001: 75-147). La injusta introducció del duc de Anjou tracta fins i tot els filipistes d'idòlatres i assegura que «Déu és de la part dels justos». ${ }^{35}$ Encara que en el full Doctrina vigatana (s. d.) es recomanava, irònicament, no criticar el virrei, Francisco Antonio Fernández de Velasco, anomenat sovint Velasquillo, perquè la seva actuació estimulava la revolta, va ser blasmat en diversos poemes, fins i tot monogràficament. ${ }^{36}$ La Cançó nova al feliç succés dels vigatans al declarar-se per Carlos III... i l'estada del Congost (s. d.; Albareda, 1988: 34-35) va celebrar aquesta rebel-lió. En canvi, un poema filipista en castellà mitifica la mort de Gabriel Berga, oïdor de la Reial Audiència de Mallorca, a mans dels austriacistes (Pascual 2009-2010).

33. Devotos obsequiosos... (58-71), Revilla (1983: 401-403) i Comas (1985: 152-153).

34. Devotos obsequiosos...: 72.

35. S. d.: f. [2v], Rubió (1985-1986: III, 257), Comas (1981: 50-51), Gilard (2000: 331-332 i 370372) i Torras (2007: 173-174). La «Cançó a la catalana contra los castellans i botiflers» incita a fer «comprendre la justícia / als traïdors castellans», perquè s'afegeixin a l'Aliança de «portuguesos, milanesos / mallorquins i valencians, / sardos i aragonesos / inglesos i holandesos / alemanys i napolitans», amb el suport destacat d'Eugeni de Savoia i la regna Anna d'Anglaterra (Universitat de Barcelona [UB], ms. 213: f. 8).

36. Com Clamors de Barcelona al tirà govern de Velasco, Barcelona: Joan Jolis, s. a.; Invectiva al político gobierno de don Francisco Velasco: Lírico lacónico poema, Barcelona: Martín Gelabert, s. a.; Letra de Velasco, s. d. (Arxiu Històric de la Ciutat de Barcelona, Gràfics —indico les signatures d'aquesta secció perquè no figuren al catàleg informatitzat-, Romanços, I, 17); Pronòstic a la navegació de Velasco $i$ sos companys, s. d., i «Romance que se hizo el año 1705 durante el asedi[o] de Bar[celo]na, que fue asistida por las armas imperiales y catalanas, sien[do] virrey el Exmo. $\mathrm{S}^{\mathrm{r}}$. D ${ }^{\mathrm{n}}$. Franc[is]co de Velasco, contra quien se hizo el romance» (UB, ms. 213: f. 10v-12v). Vegeu també Rubió (1985-1986: III, 199-200), Comas (1981: 47-49), Ibáñez (1982: 131-149) i Alabrús (2001: 177-179). 


\subsection{Carles III i els triomfs de la Gran Aliança}

Com ha repetit la bibliografia, l'exaltació del pretendent dels Habsburg a Catalunya, bé sigui per la proclamació, l'adhesió, l'arribada o les primeres victòries, va inspirar, a vegades contrafent gèneres religiosos, diversos poemes. ${ }^{37}$ Anecdòticament, però significativa, a Palma es van atribuir a l'unicorn del faristol del convent de sant Domènec, que ja havia participat en les celebracions de la visita de Carles I i que inspira altres poetes, com Albert Burguny (1997: 189-198), unes «redondillas» i unes dècimes, justificant que eren en català atès que «solo usa del nativo y mallorquín idioma» «por no haver salido jamás de Mallorca». ${ }^{38}$

Es va agrair, a més, el suport aliat, com mostren, per exemple, les Redondillas, con remates en títulos de comedias, en que defiende un curioso la majestad

37. Per exemple, Notícies tenien los catalans de son llegítim rei, s. d. (Arxiu Històric de la Ciutat de Barcelona - $\mathrm{AHCB}$ - Gràfics, Romanços, I, 8), amb la variant Cançó nova de la alegria que han tinguda los catalans de la vinguda de nostre rei Carlos III, s. d., i Campabadal (2003-2004: II, 201-205); Lamentables veus ab les quals la fortuna, inconstant, publica a la desgràcia de Frància, aplaudint als triunfos de Carlos III, s. d. (AHCB, Gràfics, Romanços, I, 2); Memorables aplausos que, gustosa, la nació catalana dedica a son rei, Carlos III, s. d.; Cançó nova: Viva Carlos III, s. d., i Vela (2014b); Doctrina catalana d'un mestre i deixeble, amb unes dècimes en català dedicades a unes festes en honor de l'arxiduc celebrades el 1705 a la parròquia de Santa Susanna del Mercadal, de Girona, s. d., i Campabadal (2003-2004: II, 206-209); Goigs de Carlos III, que imiten els de la Mare de Déu del Roser, Barcelona: Rafael Figueró (1705), Batlle (1924: 114), Campabadal (2003-2004: II, 199-201), Escobedo (2009: 58) i Vela (2014b); Cobles a la desitjada vinguda de nostre rei i senyor Carlos III, Barcelona: Rafael Figueró, s. a.; Cobles bullicioses $i$ verdaderes que canten los catalans alegrant-se ab la vinguda de son amat rei, Carlos III, s. d.; Cant dels aucells quan arribaren los vaixells davant de Barcelona i desembarco de Carles III, s. d., aprofitant la tonada de la famosa nadala homònima; Norabona a l'Excellentíssima Ciutat de Barcelona per haver vingut en ella l'Augusto Senyor Don Carlos III, Barcelona: Rafael Figueró, s. a., Rossich i Valsalobre (2006: 371-378) i Feliu i Torrent (2011: 227-228); Cantem alabances del rei... Carlos III, rei de la monarquia d'Espanya, s. d.; Cobles en alabança de la conquista de nostre rei don Carlos III, Barcelona: Francisco Guasch, s. a. (AHCB, Gràfics, Romanços, I, 16); Romanç en assumpto que donaren a un poeta: Lo floc groc [distintiu austriacista]: Dirigit a Carlos III, als 24 d'octubre 1705, s. d.; Ensenyança que dóna la província de Catalunya a tots los moradors del regne d'Espanya i províncies adjacents, s. d. (AHCB, Gràfics, Romanços, I, 10); Obsequiosas demostraciones con que el gremio de los plateros festeja a... Carlos III...: En su feliz entrada en... Barcelona el 7 de noviembre del año 1705, amb els anagrames «SOL CAR. SAL, COR» (Barcelona: Llopis, s. a.: f. [3]); A la exaltación de nuestro finísimo amante rey Carlos III, s. d., amb una dècima en castellà i un tercet i quintets catalans, i Vela (2014b), i Ejercicios poéticos a Carlos III y Cataluña, s. d., també amb algun poema en català.

38. S'allunyen bastant de les pretensions del títol de l'opuscle: Pindáricas flores que a la reina de ellas, la Virgen santísima del Rosario, y a la flor del imperio, Carlos III..., consagra un balear ingenio, discurriendo sobre la feliz restitución del Reino de Mallorca al suave dominio de dicho católico monarca, que ocho días precisos antes de la fiesta principal del rosario se ejecutó sin los estragos marciales que se temían, por influjos (según piadosamente se cree) de la santa devoción que al presente en dicho reino summamente florece, s. 1.: Emprenta del Real Convent de St. Domingo, s. a., f.[5r]-[6r]). A l'exemplar de la BC amb la signatura 7-I-18/8, que, segons ha tingut l'amabilitat d'informar-me Anna Gudayol, forma part d'un volum factici ingressat amb la compra fundacional de la biblioteca de Marià Aguiló, hi ha una nota que, encara que s'hi hauria pogut imitar una lletra més antiga, no sembla seva (com m'ha confirmat Margalida Tomàs, reconeguda especialista en aquest autor), en què es data l'obra el 1707 i s'atribueix al dominicà 
de su rey Carlos III... y el inascesible valor de los catalanes i Acentos de Mireno [pseudònim pastoral encara recurrent (Brown, 1989b: 285-289), que ja havia fet servir, entre d'altres, Francesc Fontanella,] al llegar a Barcelona los primeros socorros de los altos aliados para este año de 1711: Expresados en redondillas que se rematan en títulos de comedia. ${ }^{39}$ Aquest artificiós recurs va fer fortuna, també en la literatura propagandística, com il-lustren, igualment, altres poemes (alguns estudiats per Escofet 1923-1927[1932]).

Antoni Comas (1981: 55-59 i 1985: 146-150) ja va remarcar l'especial interès del romanç Còpia d'una carta escrita al Principat de Catalunya ab la qual li supliquen alguns que es troben en Castella i altres parts baix lo tirà govern de la França los deslliure de la esclavitud que pateixen, posant-los a la... obediència de... Carlos III, perquè aquesta perspectiva nostàlgica, a més de justificar l'expansió hispànica, afavoreix un patètic elogi de Catalunya, amb referències històriques, i del projecte austriacista:

\author{
Fortalesa inexpugnable \\ que, entre valls i entre muntanyes, \\ la naturalesa sola \\ forma fossos i muralles; \\ tu que, d'ella afavorida, \\ no necessites que Pal-las \\ en sa escola militar \\ t'ensenye a jugar les armes; \\ en la fe, la més constant, \\ devota sempre a les ares \\ del sagrament, defensora \\ de la Concepció sens màcula; \\ Tu que has dat lleis a l'Europa, \\ pues ta política rara \\ han seguit los estrangers, \\ servint-los de nord i pauta; \\ a tos comptes carinyosa,
}

Tomàs Barceló, professor a la Universitat de Mallorca de retòrica, entre altres matèries, i autor d'Arte de poesía castellana (C. Simó, 1981). La identificació coincideix amb Bover (1868: I, 69-70), que esmenta un altre llibre del mateix escriptor aprovat aquell any: Real retrato del austriaco monarca y rey legítimo de las Españas, D. Carlos III..., propuesto al balear cariño que por la dilatada ausencia de tan amable monarca suspiraba: Con su epígrafe y auténtica inscripción según el común estilo de los discretos notarios estipulada, en que se afianzan al regio original, por sus reales prendas y, con los faustos auspicios del Ssmo. rosario, gloriosos progresos: Delineado sobre la tela de una panegírica oración que dijo el R. P. F. Tomás Barceló... en la celebridad festiva que... consagró en el magnífico templo de dicho real convento el discreto Colegio de Notarios, domingo a los 7 de noviembre de 1706, por la feliz restitución del reino Balear al legítimo y suave dominio de tan deseado monarca, s. 1.: Emprenta del Real Convent de St. Domingo, s. a., amb anagrames escrits per l'autor a les p. 55-58.

39. Respectivament, Barcelona: Francisco Guasch, 1705: f. [1r] i s. d. (AHCB, Gràfics, S. P. E., 13). Es va dedicar específicament un Romance panegíric a la reina Anna d'Inglaterra... per haver deslliurat ab sa gran flota a tot lo Principat de Catalunya... de la tirana opressió de França, posant-lo a l'obediència de... Carlos III, Barcelona: Joan Jolis, s. a., i Comas (1981: 49). 


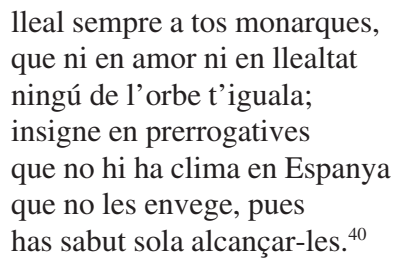

Com s'ha ressaltat també, els nous triomfs austriacistes van inspirar abundants poesies, en alguna de les quals es va recórrer encara, tot i que a vegades de manera burlesca, a la rica tradició dels pronòstics (G. Simó, 1979; Escartí, 1991), sovint invocant signes sobrenaturals (en particular, astronòmics) ${ }^{41}$ Es mitifica, en especial, el virrei Georg von Hessen-Darmstadt, la mort del qual el 14 de setembre de 1705 a Montjuïc, ferit en combat, va inspirar nombroses elegies, estimulades per actes fúnebres. ${ }^{42}$ En la Festiva aclamación que la siempre fiel y leal villa de Reus celebró en acción de gracias por la alegre venida a Cataluña de... Carlos III de Austria... y por los felices progresos de sus justas armas, el día VIII de

40. Fullets Bonsoms, de la Biblioteca de Catalunya, 5705 i 5706, que en aquest passatge només difereixen en l'ortografia, f. [1r]. Tinc present l'edició de Comas (1985: 147), en què s'ha omès el setè vers i es prescindeix dels tres últims. Vegeu també Gilard (2000: 340-341, 358-360, 363 i 368-369).

41. UB, ms. 213: f. 8r-9v; Cançó del feliç succés que tingueren les armes del nostres rei Carlos III en lo siti de Barcelona i presa de Montjuïc, Barcelona: Francisco Guasch, s. a.; Cançó ab la qual breument se relata lo siti de Barcelona del corrent any 1706, s. 1., «vense en casa de Joan Pi [...] i en la de Francesch Ascona», s. a.; Primicol de les heroiques proeses catalanes en lo siti de Barcelona que posà lo duc d'Anjou i tot lo poder de França lo any 1706, Barcelona: Francesc Avinyó, s. a.; Goigs de la Puríssima Concepció de Maria Santíssima col-locada en la real columna que en lo Born de l'Excel-lentíssima Ciutat de Barcelona erigí la Catòlica Majestat de Carlos III...: Dia 20 de juny de 1706, Barcelona: Joan Jolis, 1706, i Vela (2014b); Profecies $i$ documents que va donar un venerable ermità al duc d'Anjou al pèrdrer-se este en lo bosc que se li féu en l'Excel-lentíssima Ciutat de Barcelona lo any 1701: Dites profecies se acabaran de veure complertes... en est any de 1706, Barcelona: Giralt Estamper, s. a., Rubió (1985-1986: III, 188) i Comas (1981: 51); Lletres curioses de la bonaventura que digué una gitana a Carlos III quan partí de Viena a Espanya, Barcelona: Francisco Guasch, 1707, Rubió (1985-1986: III, 188190), Comas (1981: 51-52), Escobedo (1995: 143-144 i 2009: 60-62) i Brown i Melchor (1995: 60 i 160-163), en què es consideren aquest poema i el següent d'«atribució dubtosa» a l'esmentat Joan Ferrer Gualbes de Bonaventura i Copons, un dels cognoms del qual coincideix amb la denominació del gènere; La bonaventura que digué la gitana imaginària al duc d'Anjou al partir-se de París per lo regnat d'Espanya, seguida d'uns Elogios a la Albufera, célebre por llevarse la atención de la Majestad Excelsa del Señor Carlos III, Barcelona: Joseph Llopis, 1707, i Brown i Melchor (1995: 161-163), i Palinòdia gallihispana [gal-lohispana, però jugant, com és freqüent, amb l'animal que simbolitza els francesos] obligada cantar a impulsos del valor i fidelitat de la nació catalana: Romance curiós, Barcelona: Joseph Llopis, 1706, quartetes 270 i 285. A la 210, com ja va remarcar Rubió (1985-1986: III, 183), s'esmenta Josep Romaguera, que es va sumar a l'austriacisme, encara que s'adaptarà al règim borbònic (Soberanas, 1973). Albert Sánchez Piñol, en la novel-la històrica Victus (2012: 348), imagina que, en els preliminars del setge de Barcelona, es llegeix el llibre d'emblemes d'aquest autor Ateneu de grandesa sobre eminències cultes (1681).

42. Rubió (1985-1986: III, 102), Comas (1981: 554), Ibáñez (1982: 124-129), Gilard (2000: 393-401) i Alabrús (2001: 174-176). 
noviembre del año 1705, y llanto fúnebre en el día IX de dicho mes y año por la sentida muerte del serenísimo señor D. Jorge... Lansgrave de Hassia, unes anònimes dècimes ponderen fins i tot que «imità el Redemptor, / en traure'ns d'esclavitud, / i, per a dar-nos salut / llibertat i alegria, / mostrant sa gran valentia, / donar la vida ha volgut» (51-52; Iglésies, 1954: 17). A més, un jeroglífic català juga, com va ser freqüent, amb el cognom: «Vos suplica, / catalans, a Maria un Ave, / Lansgrave, en tan grave Lans; / en tan grave Lans, Lansgrave» (53). En Amantes llamas en flamante pira (ilustrada con diversos poemas) erigida, dia 14 de diciembre 1706, en la iglesia parroquial de San Pedro de Gavá para el ínclito y serenísimo Señor don Jorge... Landgrave de Hasia Darmstadt, també s'apleguen poemes en català, entre els quals més jeroglífics, en castellà i en llatí. ${ }^{43} \mathrm{Com}$ remarcava ja «Elogios al Prince de Darm $<$ e $>$ st $<\mathrm{r}>\mathrm{ad}[\mathrm{t}]$, d[o]n Jorge Langrave d'Hàssia, Sereníssi[m] Senyor» (UB, ms. 213: f. 4r-7v), la seva absència serà compensada pel seu germà, que protagonitza Elogis deguts al Sereníssim Senyor don Enric Landgrave d'Hàssia, príncep Darmstadt (s. d.; Comas, 1981: 49).

L'heroïcitat femenina adquireix relleu en el conflicte. ${ }^{44}$ Entre altres referències, es canta específicament en el plec solt Proeses que les barceloneses dones han ostentat en lo siti de l'any 1706 (s. d.):

\author{
Estes la sang detenien \\ que els queia, qui a raig, qui a gotes; \\ aquelles tapaven nafres, \\ que són de la Fama boques. \\ Unes, del mig de les bales, \\ a sos patrícios socorren; \\ altres prenien lo ferit \\ i a Barcelona el retornen. [....] \\ I, encara que elles trobassen \\ a ses companyeres mortes, \\ no per això desmaiaven, \\ antes apar que envidioses \\ de veure que havien dat \\ més que elles, com a lleones \\ al major perill se entraven, \\ causant envídia no poca \\ al mes valerós soldat, \\ al capità de més honra. ${ }^{45}$
}

43. Respectivament, Barcelona: Jaime Surià, s. a., i Barcelona: Rafael Giró (1707: 3-8), i Campmany (1999). En diverses solemnitzacions, solia fer-se gala de poesia artificiosa (Grilli, 1985; Rodríguez, 1987; Galindo Blasco, 1994; López Poza, 1994; Mínguez, 1997; Zapata, 2000; Bonaventura, 2010; Cuesta, 2011).

44. Nash (2000), Alabrús (2010ab), Gabancho (2014) i Massanés i Serra (2014).

45. F. Bon. 569 i 12727, [Barcelona]: Bartomeu Giralt, s. a., i 2724, s. d.: f. [1v]-[2v], que en aquest passatge només difereixen en l'ortografia. En l'edició del F. Bon. 5727, a més d'ometre's la darrera lletra d' «envidioses», s'usa l'article determinat, en lloc del possessiu, davant de «companyeres». 
L'autor voldria tenir la mà del «Gran Garcia», «el polit Fontanella» i el «Rector de Bellesguard», nom de ploma de Joan de Gualbes, «que este sigle gosa», «o la que vui se nos mostra per Miracle» (f. [1v]-[2r]). Aquest darrer passatge s'ha interpretat com una autoatribució (Brown i Melchor, 1995: 39; Baró, 2005: 64), per bé que Rossich (2010: 516) ho ha considerat no provat, tot i que admet, com Rubió (1985-1986: III: 15-16; Ruiz, 1954: 376), l'al·lusió a un escriptor anomenat Miracle, que suggereix que podria tractar-se de Pau, continuador de la Comèdia de Santa Bàrbara, de Francesc Vicent Garcia, i abat de Santes Creus —a més, va ser catedràtic de filosofia de la Universitat de Tarragona i va morir el 29 de gener de 1713, havent publicat diversos llibres (Miquel, 1961) — o un altre monjo d'aquest convent, Bernardó de segon cognom.

Es canta també específicament la victòria del 7 de setembre de 1706 en un altre setge de les tropes francoespanyoles, iniciat poc després de l'abandonament del de Barcelona, en els decasíl-labs apariats de la Cançó nova sobre lo siti $i$ batalla de Torín, capital de la Savoia (al to de La bella Lisarda [musicada per Andrea Falconieri]), en què s'adverteix: «Deixau la porfia, gavatxs obstinats». Fins i tot, s'imagina la Lamentació i despedida del duc d'Anjou, rei d'Espanya fingit, en què, acomiadant-se també d'Aragó i Castella, manifesta la voluntat de dedicar-se a la vida contemplativa; la rebla una Resposta i llicència, en què es desitja que marxi de seguida, després de tornar el que ha robat. ${ }^{46}$

Un romanç en català canta el triomf en la batalla d'Almenar del 26 i 27 de juliol de 1710, bo i planyent-se per la mort del comte de Nassau, i la victòria a Saragossa el mes següent és recordada en la «Cançó contra los botiflers que se tragué de Castelló d'Empúries fins a Pau», en què se somnia la recuperació del Rosselló (UB, ms. 213: f. 13 i 25v-26v). Es replica una letrilla contra Guido von Starhemberg amb un romanç en castellà que recorda aquestes i altres victòries, destacant l'entrada a Madrid i contraposant el capteniment de les seves tropes als abusos de les castellanofranceses (ibid.: f. 19v-21v).

El romanç Piadoso vaticinio a que motivan las moscas que se han visto en el sepulcro de san Narciso, de Girona, que actualitza la cèlebre llegenda medieval antifrancesa (Valsalobre, 2003 i 2004), que ja recordava el Primicol (f. [1v]), adverteix que només piquen els filipistes. ${ }^{47}$ Daten el plec els penosos «diez años de riñas», l'abandonament de Madrid per Felip V i el repte a Vendôme i Noailles (f. $[1 v]-[2 r])$. El rector de Centenys recordava l'aparició d'aquests insectes en obrir el sepulcre, com s'acostumava el darrer dia de l'octava dedicada al sant, el 5 de novembre de 1710 (Constans, 1947; Colomer, 1981: 539; Cortadellas, 1998: 503), però la ciutat no resistiria el setge iniciat poc després, indefensa a causa de la fracassada ofensiva peninsular austriacista.

Una crida del duc de Noailles als catalans després de la caiguda de Girona el 14 de gener de 1711 és replicada per una «resposta», ambdues en català i en una

46. Girona: Francisco Oliva, respectivament, s. a. i s. d. En la primera obra, sembla que s'al-ludeixin les Profecies i documents citats. Vegeu també Rubió (1985-1986: III, 188-190) i Comas (1981: 52-54).

47. Barcelona: Francisco Guasch, s. a. (AHCB, Gràfics, Gua. 4), i Torras (2000: 83). 
forma similar a la codolada (apariats de set i quatre síllabes, a excepció del primer heptasíl·lab, sense rima) (UB, ms. 213: f. 14r-19r). El maig d'aquell any, s'escriu una «Ritma burlesca i satírica que verdaderament desenganya els més obstinats botiflers, que ab proposicions sofístiques i fal-laces defensen lo partit del duc d'Anjou, negant la potència (contra la tomística filosofia) de Carlos III en la monarquia d'Espanya» (ibid.: 21v-25v).

\subsection{L'aïllament i la derrota dels catalans}

En Dolorosos acentos de las tres afligidas Musas del barcelonés Parnaso con que el excelentísimo y fidelísimo consistorio de la Diputación de Cataluña acompañó las tristes y religiosas exequias de la cesárea majestad de Joseph primero, augustísimo emperador de Alemania, hermano de nuestro rey y señor Carlos III: Celebradas en el real y acostumbrado salón de San Jorge de dicha Diputación, día 13 de julio de 1711, abunden els poemes en català, entre els quals una octava reial en què es tracta la Parca de covarda per no haver-se atrevit a matar-lo en algun combat (f. [6v]; Rossich i Valsalobre, 2006: 379). ${ }^{48}$ Encara que una dècima també catalana suggereix que la renúncia de Josep a la corona hispànica es va produir pressentint «esta tragedia mortal» (f. [8v]), una altra titulada «Expressa Catalunya ser la primera en lo sentiment de la mort del senyor Josep primer, ab reflexió a la pròpia divisa» (f. [9v]) podria ser, com va remarcar Antoni Comas (1981: 554-555 i 1985: 146), «maliciosa o profètica, o totes dues coses alhora», perquè aquesta defunció comportarà l'elecció de Carles com a emperador d'Alemanya i, de retruc, l'abandonament dels catalans.

Per boca d'Elisabet Cristina, una epístola en vers, Carta que escribió la señora archiduquesa a su querido esposo don Carlos, archiduque de Austria, en demanava el retorn (Amat, 2014: 79-80) i, un cop absent també ella, que havia estat molt lloada no merament com a consort, una Carta que la afligida Barcelona, después de cuatro meses que gime oprimida de estrecho asedio, en los primeros días del mes de diciembre de 1713 escribe a la augusta emperatriz y reina, su señora, en este romance de arte menor, per bé que li recordava, a més del deure dels governants d'escoltar els súbdits, que aquesta ciutat havia estat «el rico Ofir» i el «pensil» dels seus «arrullos» amb el rei (f. [2r]), l'associava a la Mare de Déu (amb una il·lustració de la Immaculada, el qualificatiu de «divina» i el tractament de «madre»), fins al punt d'haver d'esclarir la preeminència dels protectors sobrenaturals. ${ }^{49}$ De totes maneres, d'acord amb una llarga tradició, són invocats sovint. ${ }^{50}$

48. Barcelona: Rafael Figueró, 1711.

49. Barcelona: Francisco Guasch, s. a. (AHCB, Gràfics, Gua. 19): f. [1r]-[2r], i Gilard (2000: 221 i 377-378).

50. Com il·lustren, per exemple, «Deprecació a la Puríssima contra los enemics» (UB, ms. 213, f. 74v-75v); Cobles en honor de la gloriosa verge i màrtir santa Eulàlia, Barcelona: Bartomeu Giralt, 1711; Goigs de la miraculosa imatge de Nostra Senyora de la Pietat del portal de Mar, Barcelona: Joan Jolis, 1712, i Vela (2014b); Gozos del invictísimo martir S. Jorge, abogado de la Deputación del excelentísimo y fidelísimo Principado de Cataluña, Barcelona: Francisco Guasch, 1713, i Vela (2014b); un poema de Gualbes dedicat a una relíquia d'aquest sant (Brown 
Òbviament, els catalans van adquirir més protagonisme en trobar-se abandonats a la seva sort, encara que la situació era molt precària. En un poema adreçat als sis primers consellers nomenats el 30 de novembre de 1713 (destacats en els ecos: [Rafael] Casanova $<\mathrm{s}>$, [Salvador] Feliu [de la Penya], [Ramon] Sans, [Francesc Antoni] Vidal, [Josep] Llaurador i [Jeroni] Ferrer), s'insten els tres darrers, però, implícitament, també els altres, a fer «de l'honra cabal», a fi d'assolir «fama, justícia i honor». ${ }^{51}$ Destaca la cançó transmesa oralment consagrada a Francesc Macià i Ambert, Bac de Roda, que qualifica aquest militar austriacista, penjat a Vic el 2 de novembre de 1713, del «cavaller» «més noble de la Plana», bo i maleint els traïdors i subratllant, a fi de distanciar-se del gènere bandoleresc, que, lluny de ser un «lladre», va morir perquè «visqués tota la pàtria». ${ }^{52}$ També van esdevenir populars altres resistents, com Pere Joan Barceló, «Carrasclet» (Barceló, 2003).

L'autor de la «Resposta d'una carta qu[e] [e]s rebé de Viena en 1714», romanç que remunta al juliol el «pes» que es volen treure els catalans (probablement en al-lusió de l'inici del setge de Barcelona l'any anterior), tot i reconèixer el fred i les desercions cap a la borbònica Mataró, minimitza les penúries d'abastiment de Barcelona, es declara «català» «de tots quatre costats», renega dels pactes de les potències estrangeres (en particular, del tractat d'Utrecht), assegura que es batria amb els llegendaris Gaiferos i Rotllà i manifesta les esperances en la Coronela,${ }^{53}$ el marquès de Poal (Antoni Desvalls), Sebastià i Amador Dalmau, el

i Melchor, 1995: 117; Alcoberro i Campabadal, 2014: 162); Afectuosos clamors en los quals se implora lo socorro dels sants protectors de la ciutat de Barcelona per lo siti de l'any 1713, Barcelona: Francisco Guasch, s. a., i Vela (2014b); Anima Barcelona a sus hijos e implora el poderoso patrocinio de su ínclita patrona santa Eulalia al querer sacar su invencible bandera hallándose con tres brechas en agosto de 1714: En este romance de arte menor, Barcelona: Francisco Guasch, s. a.; Goigs del gloriós bisbe, màrtir i doctor S. Policarpo, Barcelona: Joseph Llopis, 1714, i Vela (2014b) (a l'exemplar de la BC Goigs 2/65, s'ha precisat a mà la data de 26 de gener) i Goigs de Nostra Senyora de la Llibertat, Barcelona: Joan Pau Martí, 1714, que identifiquen una imatge de Maria de la capella d'en Marcús amb aquesta advocació (Comas, 1981: 232-235 i 1985: 150-151; Martí, 2014; Vela, 2014b).

51. UB, ms. 213: f. 55r, i Alabrús (2001: 351-352). Vegeu també les referències a l'elecció del Manual de Novells Ardits (1975: XXVIII, 109, 111 i 114-115), Campabadal (2009: 377) i Alcoberro i Campabadal (2014: 97-98 i 168). Més enllà del requeriment del poema, durant el jurament els consellers oïen la sentència d'excomunió, que els seria aplicada si no actuaven honestament.

52. Comas (1981: 59), Pladevall (1996), Roviró, Aiats, Girbau i Roviró (2004: 36-37) i Barniol (2007). Aquesta cançó va ser traduïda pel falangista Félix Ros, en la seva Antología poética de la lengua catalana (puesta en versos castellanos), llibre en què es qualifica la guerra de Successió, amb el consegüent «diktat del Decreto de Nueva Planta», de «puñalada trapera» (Ros, 1965: 142-143 i 90). L'any següent s'edita El poble, de Miquel Martí i Pol, encara que va ser escrit entre 1956 i 1958, en un poema del qual, «Meditació primera», s'esmenta reiteradament el «carrer d'En Bach» de Roda de Ter (Martí i Pol, 1989: 166). Aquest poema no es va avançar en l'edició de Papeles de Son Armadans, 61 (abril 1961), 59-76.

53. En el plec En elogio de la insigne y valerosa Coronela de la excelentísima ciudad de Barcelona y demás defensores de dicha plaza: Romance endecasílabo, Barcelona: Francisco Guasch, s. a., es comparen aquestes milícies a Alcides, Mart, Pal-les i Argos, les dones a les Amazones i, prodigant altres correlats clàssics, es lloen també els oficials, el coronel (el conseller en cap), la Diputació, el «comandante general» (Antoni de Villarroel) i els altres generals. 
coronel Francesc Rau i Ermengol Amill, «de la pàtria, redemptors» (UB, ms. 213, f. $73 r-74 v)$.

Arran de la Còpia d'una carta escrita per lo Il-lustre Marquès del Poal als Magnífics Senyors Priors, Cònsols, Proms dels Col-legis i Confraries de l'Excellentíssima Ciutat de Barcelona, datada a Borredà el 3 d'agost de 1714, el romancet Carta en resposta..., que figura escrit pel «menor soldat» de la Coronela, apressa l'ajut ofert per Desvalls, perquè, tot i que «a penes / cosa entera hi ha», resisteixen, més èpicament que «el saguntins», arriscant la vida «per la pàtria i la llibertat» en les bretxes i fortins, ajudats fins i tot per nens «dant pólvora i bales» (f. $1 r-2 r) .{ }^{54} \mathrm{El}$ setge, però, no es va trencar i abundaven les privacions, sobre les quals va ironitzar Gualbes en una dècima:

$$
\begin{aligned}
& \text { Penúria de carn tenim, } \\
& \text { penúria de vi pasam, } \\
& \text { tot és car quan envocam, } \\
& \text { de oli, peix y foch patim; } \\
& \text { gloriosas faltas sentim } \\
& \text { per justa causa final, } \\
& \text { gastam deu per un ral, } \\
& \text { però ab ferma fe a porfia, } \\
& \text { pasant per la Bocaria } \\
& \text { nos ne anam a l'Hospital. }
\end{aligned}
$$

El jurista Manuel Mas i Soldevila, autor de la Relació del siti de Barcelona de l'any 1713-1714, compendia l'isolament i la derrota de Catalunya en un desolat poema, amb el freqüent símil dels naips (Étienvre, 1981-1982 i 1990; Garcia Espuche, 2009b), utilitzat també en altres poesies polítiques de l'època:

\author{
Nostras antigas cartas, rubricadas \\ ab tanta sang, compradas ab la vida, \\ entenent que de Utrec en la partida \\ foren, si se entaularen, barrejadas, \\ Barcelona, per si, las ha entauladas, \\ a Déu y a la ventura reduhida; \\ arma son joc y luego se li envida \\ per un taür de flors que a Espanya ha dadas. \\ Lo resto, ab tretse, Barcelona llansa; \\ mes, com a un trist catorse que li cau, \\ son rey no acud per guerra ni per pau,
}

54. Barcelona: Joan Pau Martí, 1714, i Barcelona: Francisco Guasch, s. a., respectivament. Vegeu també Rubió (1985-1986: III, 184-185) i Torres (2007: 372), i Suspiros de Barcelona encaminados al Principado, que se está dormido y sin moverse contra el enemigo que le oprime, Barcelona: Francesc Guasch, 1714.

55. Brown i Melchor (1995: 114).Vegeu també Rubió (1985-1986: III: 130) i Comas (1981: 653). 
y, al taür, ab espasas acud Fransa.

Perd lo joc, perd quant té, perd la esperança, que és lo que, de jugar sas armas, trau. ${ }^{56}$

\subsection{La postguerra}

Alguns van abandonar el bàndol austriacista abans de la derrota, la data de la qual depèn de la ciutat, com possiblement va fer Carles Gassulla d'Ursino (Escartí, 2013). Altres, com Josep Vicent Ortí, van poder manifestar l'antic filipisme en entrar les tropes borbòniques (Escartí, 2007; Furió, 2001: 116; Sansano, 2001). Evidentment, el vencedor serà aclamat i reverenciat per molts, amb convicció o bé fingint, i presidiran els espais públics retrats o divises seus, com les estàtues i l'escut reial ressaltats en les «Coples de l'alameda» de València (Martí Mestre, 2013: 251). De totes maneres, a vegades, es retraurà el conflicte, com en una glossa amb motiu de la mort, el 14 de febrer de 1714, de Maria Lluïsa de Savoia, en què es recorda que «son regnat fou turbulent / ab moltes alteracions»..$^{57}$

Un presoner del castell de Peníscola, que podria tractar-se de Pere Vicent Zabata o algun altre poeta relacionat amb Sant Mateu del Maestrat, el 1711 escriu uns goigs i una oració paròdics en dues versions, una en contra del governador Sancho de Echevarría i una altra a favor, en la primera de les quals remarca:

En este temps tot són crits,

llantos, suspirs y afliccions,

pues no es veu sinó a montons

pobres, presos y afligits. ${ }^{58}$

S'han conservat manuscrits diversos poemes del «Rector de Garriguella», domer d'aquest poble, identificat amb Manuel Gibert, de Peralada, en un treball

56. Alcoberro i Campabadal (2014: 119). Vegeu també Rubió (1985-1986: III, 175-177), Comas (1981: 711-715 i 1985: 151-152), Campabadal (2003-2004: II, 209-210) i Alcoberro, Camprubí i Campabadal (2009: 31). Segons la filipista Relación de la Guerra de Sucesión de Cataluña, a la caiguda de Barcelona el 1714 «salieron» uns «puercos versos», que «expresan bien» la «fatalidad» dels catalans: «España el culo del fraile, / los fueros la limpiadera, / la eslavitud necesaria / y toda la Liga mierda» (Alabrús, 2006: 124).

57. Sermón fúnebre en las exequias que celebraron el... cabildo y la... ciudad de Urgel en la muerte de la... reina de las Españas, doña María Luisa Gabriela de Saboya: Díxole [el 21 d'abril] y sácale a luz de orden y a expensas de dichos comunes, con una relación succinta de dichas exequias y poesías que se pusieron en el túmulo, el padre Rafael Cassany, de la Compañía de Jesús... en el presente año 1714, s. 1.: Josep Teixidó, s. a: 7-8, 14-15 i 17-18, en què, a més de poemes en castellà i llatí, se'n recullen altres de catalans: una octava reial —curiosament, en boca de Felip V—, dos sonets, un d'ells amb «monosíl-labos forçats», i uns desapercebuts «ecos consolatoris», ovillejos en resposta dels «lastimosos de un español». Vegeu també Rubió (1985-1986: III, 186) i Comas (1981: 556-557).

58. Ms. 3619 de la BC: f. 135v, i Querol (2011: 494-498). La versió laudatòria d'aquesta estrofa és: «Sosseguen-se ia los crits, / cessen llantos i afliccions, / pues que perdona, a montons, als miquelets afligits» (f. 138v). 
inèdit de Josep Playà i Maset. ${ }^{59}$ Després d'uns nou anys de ser partidari de Carles III (Girbal, 1887: 291), veient-lo perdedor (ibid.: 343-345), havent estat fugitiu (ibid.: 342-343) i coneixent que «sia francès o alemany, / espanyol o portuguès», «rei / és aquell» que li pot fer «dany» (ibid.: 292), manifesta en diversos poemes, ateses les circumstàncies i amb un punt d'ironia, el seu penediment de l'austriacisme, atribueix la poesia propagandística a la recerca de la fama literària (ibid:: 342) i es compromet a escriure «per desengany dels culpats» (ibid.: 341). Per exemple, en aquestes dècimes adreçades al comte de Fiennes, comandant de Girona i el seu districte, assegura que mereix «ser perdonat / i no fer-me posar pres», adduint:

\author{
No té tantes pedres Ter \\ com paraules he gastades \\ en las cançons que he dictades \\ per un senyor molt sagrat \\ que sens amor ha deixat \\ els amics en les pedrades. \\ Ni ganivet ni punyal, \\ ni pistoles ni escopeta \\ ha portat aquest poeta, \\ que fonc molt imperial; \\ però no fou deslleal, \\ com molt altres, en obrar, \\ perquè sòls pogué pensar \\ en fer versos i cançons \\ perquè nines i minyons \\ se poguessen alegrar. [...] \\ No faré més poesies \\ en dependències de reis [...] \\ Són grans les melancolies \\ que los versos me han causat, \\ però avui, desenganyat, \\ determino retirar-me. [...] \\ En ma casa retirat, \\ procuraré solament \\ viure com un penitent \\ que, posat en la muntanya, \\ no sap si França o Espanya \\ són a llevant o a ponent. ${ }^{60}$
}

59. Girbal (1887, en el poema de la p. 290 se'n declara el nom), ms. 213 de la Universitat de Barcelona (s'hi aporta ja el cognom «Gibert»», f. 63v), Albareda (1993: passim), Rossich (1999) i sengles entrades sobre Gibert per a Bou (2000: 320) i Broch (2008: 445), Gifre (2012: 255) i Padrosa, s. a.

60. Girbal (1887: 290-291). Al ms. 213 de la UB, es recullen dos poemes que s'esclareix que van ser escrits en l'«ermita de $\mathrm{N}^{\mathrm{a}} \mathrm{Sr} \mathrm{a}^{\mathrm{a}}$ del Corredor»: en el primer (reproduït a Girbal, 1887: 345-349), es 
Plasmen la decepció popular el dístic «Carlos Tres i Felip Cinc / m’han deixat ab lo que tinc», ${ }^{61}$ que comenta la imatge d'un home nu, i la quarteta següent:

\author{
Els botiflers i maulets \\ bé nos feren la tirana: \\ uns, esquilant-nos del tot, \\ $i$ altres, venent-nos la llana. ${ }^{62}$
}

Ja no sols la producció i difusió d'escrits contraris al rei, sinó també el fet de posseir-ne o no delatar els que en tenien era perseguit, com il-lustra un edicte signat a Barcelona el 9 de maig de 1718:

Y, habiéndose experimentado que, aunque, con edictos de 12 de marzo de 1716 y de 13 de deciembre de 1717 , está con las mayores y más graves penas prohibido el retener y mantener papeles sediciosos, libelos infamatorios, canciones, alegatos jurídicos, poesías, narraciones históricas y otros cualesquiera libros, papeles y cuadernos concernientes al Estado y que por algún modo sean contrarios al legitimo vasallaje y debida obediencia de su majestad, mandándolos entregar bajo cierto término al escribano principal de cámara de la Real Audiencia, no se ha cumplido enteramente con lo dispuesto en ellos, antes bien, habiéndose después introducido en este Principado diferentes papeles de los expresados [...]. Ordenamos y mandamos que ninguna persona de cualquiera estado, grado, calidad o condición que fuere no sea osada de retener y mantener libro, manifiesto, ni papel alguno, así impreso como manuscrito, de los arriba expresados u otro cualquiera que pueda perturbar la paz y quietud del Principado o seducir los ánimos de la más exacta obediencia; porque serán tratados como sediciosos, perturbadores de la paz pública y, consiguientemente, como reos de lesa majestad, aplicándoles las penas correspondientes a tan enorme delito. [...] Y así mismo mandamos que, si alguno supiere quien tiene papeles de los referidos, lo deba denunciar a la justicia, bajo las mismas penas y otras arbitrarias, con apercibimiento de que, si se justificare o probase por medio de testigos o de otra legítima prueba que alguno ha tenido o retenido después de los referidos términos algunos de dichos papeles, sin haberlos entregado o bien los hubiere comunicado o esparcido, incidirá en las mismas penas y delito de lesa majestad, aunque no se encuentren en su poder. ${ }^{63}$

queixa que, fins i tot durant la guerra, «la terra / mai és estada, / com ara, tan estragada» i, en el segon, es reafirma en el seu retir de la política contradient la maledicència. No manca tampoc algun filipista penedit d'haver escrit poesia contra Carles III (vegeu, per exemple, el poema del ms. 213 de la UB, f. $9 v-10 v)$.

61. Llombart (1879: XXIV), Comas (1981: 34) i Blasco (1985: 173).

62. Sanchis Guarner (1985: 161 i 2001: 67-68; citant Tipos, modismes y coses rares y curioses de la Terra del Gè, de J. Martí Gadea, València, 1906, I, p. 254), Comas (1981: 34) i Blasco (1985: 173).

63. Don Francisco Pío de Saboya..., gobernador y capitán general de este ejército y Principado de Cataluña: Porque ha sido costumbre detestable de los enemigos del rey... y de los parciales de ellos... formar y esparcir por Europa papeles inciertos e irreverentes a su real persona... con el solo fin de inquietar y sublevar los ánimos de los vasallos, s. d.; es troba aplegat en el 
No mancarà, però, poesia austriacista en l'exili ni en la clandestinitat, com diverses poesies valencianes (Blasco, 1985: 161-173), un romanç en castellà sobre el triomf contra els turcs el 5 d'agost de 1716 a Peterwardein de les tropes de Carles VI, comandades per Eugeni de Savoia (UB, ms. 213: f. 108r-111v), l'Epopeya panegírica (Nàpols, 1718), de Vicent Díaz de Sarralde, també arran de la Guerra Turca (Alcoberro, 2007c), i les «Reflexions d'Alberoni en les mars i terres de Sicília», en què s'imagina el penediment d'aquell influent cardenal desterrat el 1719 després de fracassar l'intent d'ocupació espanyola d'aquesta illa (Alcoberro, 2007a).

A més de satiritzar-se el nou sistema borbònic (Molas, 1988), s'al-ludeix a la guerra de Successió i les seves conseqüències (Brown i Martínez, 2014: 140-144). Agustí Eura, en una dècima, havia simbolitzat la condolença celestial per les penúries dels catalans durant el darrer setge en la decapitació de l'estàtua de santa Eulàlia de la baixada de la Presó (actualment de la Llibreteria) a causa «d'una bomba la ruïna» (Eura, 2002: 493-495; Comas, 1981: 676), fet que, segons el Diario del sitio y defensa de Barcelona (Alcoberro, Camprubí i Campabadal, 2009: 466; E. Pujol, 2014: 202), es va produir el 26 de maig de 1714. En una altra, es plany:

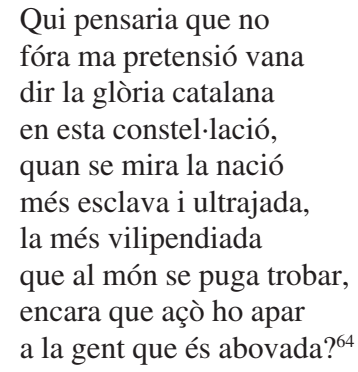

Aquest escriptor, que entre 1729 i 1732 va ser prior del convent dels agustins, el qual va patir diverses demolicions perquè es trobava en l'àrea militar de la Ciutadella, en un poema en castellà sol-licitarà a Felip V, emparat en el caràcter religiós de la demanda, que no enderroqui, pel mateix motiu, la capella de la Pietat, advocació que relaciona amb la clemència que han de tenir els governants, si bé acceptant que almenys en compensi la pèrdua amb un nou temple (ibid.: 519-523). Malgrat tot, esdevindrà predicador de la cort i bisbe d'Orense, tot i ser vetat, però, per a bisbats catalans (vegeu també Valsalobre i Gratacós, 2001; Valsalobre, 2001-2002).

Via fora als adormits i resposta del Sr. Broak, secretari que fou del sieur Mitford Crow al Sr. Vallès son corresponent de Barcelona, sobre les matèries políti-

volum dels F. Bon. 10-VI-4 (document 83), juntament amb els decrets a què remet (80 i 82), el segon dels quals es va exhibir a l'exposició «La vida quotidiana a Catalunya al voltant de 1714» de la BC. Vegeu també Blasco (1985: 158-159).

64. Eura (2002: 496). Vegeu també Rubió (1985-1986: III, 145-146) i Comas (1981: 676). 
ques presents es clou amb un sonet en italià, la versió catalana del qual tanca la Segona resposta... de Mr. Broak a Mr. Vallès, en què s'adverteix els alemanys, holandesos, portuguesos i espanyols:

Diga'm cada un: quin fruit pot conseguir-se

si no es desterra lo tirà d'Espanya?

Qui es llibrarà del bec, arpes i manya,

$a b$ què en Espanya el gall vol ja enfurir-se?

I si el dol català no ha de finir-se;

per vostra part, digau-me, quin bé es guanya?

En vostres guerres qui eixirà a campanya?

Presa Espanya ab son cap, tot deu rendir-se.

Folls! Que sens prevenir vostra ruïna, lo llot en vostres aigües revolguéreu!

Vostres esplets cremà un ajeno incendi!

Lo dany ja es veu! Pitjor França el maquina.

D'aquell fatal torneig que permetéreu,

serà el més tràgic jou vostre estipendi. ${ }^{65}$

Francesc Tagell o Tegell, en la Relació sobre la mort de Climent XII i l'elecció de Benet XIV (1740), arran de la presència de les quatre barres a l'escut del nou papa, confiarà en la recuperació de les glòries catalanes, evocades també en altres poemes:

\author{
Celebre Catalunya donchs festiva \\ d'un descendent la elecció gloriosa. \\ De sas armas ab ella com reviva \\ lo esplandor y la glòria ruïdosa, \\ espere puga ser que, rediviva, \\ sa grandesa retorne a ser famosa, \\ quant per fets que excedeixen la esperança, \\ solament Catalunya fa fiança. ${ }^{66}$
}

65. Editat també per Lluch (2005: 162). L'obra, que es data a Londres el 1734 i figura impresa a Barcelona «a costa dels hereus de Rafael Figueró» i a la venda «in Genova: da Sebastiano Floresta» (en la Resposta no s'explicita l'impressor ni el distribuïdor), ha suscitat diverses especulacions sobre l'autoria. Una «addició del Sr. Vallès» argüeix que «havent vertit en francès lo soneto italià ab què lo Sr. Broak termina son Via fora, és just que també coronen a Astrea les Muses catalanes vaticinant a tota l'Europa». Certament, el poema es recull en francès al final de la versió Alarme aux endormis..., llibre amb dades editorials similars, si bé s'hi indica que es publica «aux dépens d'un bon citoyen».

66. Tagell (1971: 12 i 163). He esmenat la penúltima paraula del tercer vers a partir dels manuscrits usats en l'edició. Vegeu també Rubió (1985-1986: III, 159), Comas (1981: 699 i 1985: 152-160) i Tegell (1989: 8). 


\section{Conclusió}

Malgrat que es deuen haver perdut, no sols per la fèrria censura, obres i documentació sobre diversos escriptors i sobre l'organització propagandística, aquesta panoràmica urgent, que caldria completar i aprofundir, corrobora ja una considerable incidència de la guerra de Successió en les lletres catalanes coetànies. El conflicte serveix d'inspiració, tot i els impediments que comporta i les conseqüències de la derrota. D'altra banda, l'establiment de la cort reial de Carles III a Barcelona suposa un important incentiu cultural. En consonància amb la conjuntura política, en la literatura catalana predomina l'austriacisme, que persisteix en l'exili i la clandestinitat, a pesar que es va procurar també l'adaptació al nou règim.

No sembla que el teatre en català es beneficiés directament de l'auge musical, escenogràfic i dramàtic de la cort de l'arxiduc ni del reformisme teatral borbònic, fet que contrasta amb l'estímul que va suposar per a Menorca el domini britànic. Malgrat que s'usa la llengua catalana en algun diàleg, no són en català les obres més pròpiament teatrals conegudes, entre les quals destaca la Comedia famosa del sitio de Barcelona y fuga del duque de Anjou, sobre l'autoria de la qual he apuntat noves possibilitats. A més, tenen caràcter més aviat apologètic, si bé es troben més crítiques socials, a vegades específicament polítiques, en peces en llengua catalana posteriors.

Tot i la tendència a l'anonimat, ressalten, a més de preceptistes i prosistes, poetes com Josep Romaguera, Antoni Peguera, Joan Antoni de Boixadors, Joan de Gualbes, Tomàs Barceló, Miracle, Manuel Mas i Soldevila, Carles Gassulla d'Ursino, Josep Vicent Ortí, Pere Vicent Zabata, Manuel Gibert, Agustí Eura, Francesc Tagell o Tegell... Es fan servir diversos gèneres poètics (glosses, villancets, goigs, contrafacta, cançons que reaprofiten tonades, pronòstics, epístoles, diàlegs, relacions, panegírics, epitalamis, elegies, sàtires...) i estrofismes (romanços —incloent-hi els heroics i els romancets—, decasíl-labs apariats, quartetes, quintets, sextets, octaves, dècimes espineles, sonets..., mentre que formes com la codolada, les noves rimades i l'adaptació que n'havia fet Jaume Roig es trobaven en recessió — Rossich, 1983-). Abunden també recursos artificiosos (emblemes, jeroglífics, anagrames, acròstics, laberints, redondillas amb títols de comèdia, ecos, peus forçats, monosílllabs, plurilingüisme — Rossich i Cornellà, 2014-, dobles versions...).

No manquen obres o passatges heroics, si bé no es té notícia de cap gran poema èpic d'aquest període en català (Campabadal, 2008). A més dels dirigents forans, particularment reis i nobles, es canten la revolta, sobretot la dels vigatans, la lluita col-lectiva (la femenina protagonitza les Proeses que les barceloneses dones han ostentat en lo siti de l'any 1706), les milícies de la Coronela i, especialment a la fi de la guerra, polítics o militars catalans (com Bac de Roda, Rafael Casanova, Antoni de Villarroel, Antoni Desvalls, Sebastià i Amador Dalmau, el coronel Francesc Rau i Ermengol Amill).

El Barroc impregna la mentalitat i l'estil de moltes obres, encara que s'adoptin sovint formes populars o popularitzants, sobretot en cerca de més difusió. Aquest afany divulgador contribueix a la utilització del català, per bé que, fins i 
tot en aquest ús, competeix amb el castellà i s'empra també en obres de pretensions cultes. El caràcter propagandístic sol condicionar la literatura del moment, però es troben reflexions subtils amb hàbil retòrica. La manipulació i la mitificació, que recorren a vegades a fenòmens sobrenaturals, tenen com a contrapunt la sàtira i el desengany, actitud típica del Barroc, però actualitzades per les circumstàncies. Lògicament, la literatura posterior aprofundirà el conflicte amb més perspectiva, encara que llunyanament i d'acord amb els propis interessos, com s'ha estudiat força (amb escasses referències als precedents més pròxims a la guerra de Successió). ${ }^{67}$

\section{Referències bibliogràfiques}

Alabrús, R. M. (1991). «La societat catalana durant la Guerra de Successió a través de la publicística». Manuscrits, 9, 305-324.

—(1996). «La publicística de la guerra». L’Avenç, 206, 40-45.

-(2001). Felip V i l'opinió dels catalans. Lleida: Pagès.

-(2006). Escrits polítics del segle XVIII: Tom IV: Cròniques de la Guerra de Successió. Barcelona: IUHJVV; Vic: Eumo.

—(2010a). «Les dones austriacistes i la Guerra de Successió». Pedralbes, 30, 245-266.

- (2010b). «La opinión sobre las mujeres austriacistas y el imaginario religioso en los sitios de 1706 y 1713-1714 en Barcelona». Cuadernos de Historia Moderna, XXXV, 15-34.

Albareda i Salvadó, J. (1988). «La revolta dels vigatans (1704-1705)». Ausa, XIII, 31-42.

—(1993). Els catalans i Felip V: De la conspiració a la revolta (1700-1705). Barcelona: Vicens Vives.

Alcoberro, A. (2002). L'exili austriacista (1713-1747). Barcelona: Fundació Noguera.

— (2007a). «Cantant les absoltes a Alberoni. Dos poemes clandestins de la resistència austriacista a Felip V (1719-1720)». A: Miralles, E.; Solervicens, J. (ed.). El (re)descobriment de l'edat moderna: Estudis en homenatge a Eulàlia Duran. Barcelona: UB / Publicacions de l'Abadia de Montserrat, 233-252.

— (2007b). «"Monarquia moderada" i "llibertat de la pàtria". Notes sobre el pensament polític de l'austriacisme castellà a l'exili». Pedralbes, 27, 173-196.

— $(2007 \mathrm{c})$. «Presència i ecos de l'exili austriacista hispànic a la tercera guerra turca: L'Epopeia panegírica de Vicent Díaz Sarralde (Nàpols, 1718)». Aguaits, 24-25, 73-96.

Alcoberro, A.; Campabadal, M. (ed.) (2014). Cròniques del setge de Barcelona de 1713-1714. Barcelona: Barcino.

67. Circumscrivint-me a treballs centrats en aquest episodi, vegeu Fradera (1993), Sunyer (2001, 2006 i 2014ab), 11 Setembre 2014 (2005-2014), Anguera (2008), Roca (2012), Riera Viader (2013), Simon (2013) i Roig (2014). Per posar tres exemples poètics no recollits per la bibliografia, Joan Oliver (1999: 27), citant el cèlebre poema de Guimerà «Lo cap d'En Josep Moragues», compara aquest episodi amb la mutilació de l'Estatut durant la II República; Joan Brossa encapçala amb una citació («A fora els lladres!») de Mestre Oleguer, monòleg de Guimerà sobre la Guerra de Successió, el poema «Fua», inclòs en Malviatge! (1954), i en l'«Oda al president Companys», datada el «solstici d'hivern de 1971» i publicada el 1976, l'assimila a Rafael Casanova («Divers et dreces en un sol llorer / i símbol d'una lluita sempre nova: / Rafael Companys, el Conseller, / i el President En Lluís Casanova») (Brossa 2001: 53 i 117-121) i Carlos de la Rica canta la celebració de l'Onze de Setembre de 1976 en un tríptic el primer poema del qual és en català (Rica, 1993: 98-99; Merchán, 2006: 179-182). 
Alcoberro, A.; Camprubí, X. (pr.); Campabadal, M. (ed.) (2009). Diario del sitio y defensa de Barcelona (1713-1714), València: Tres i Quatre.

Aldana Fernández, S. (1958). «Valencia y el Archiduque Carlos de Austria». Boletín de la Sociedad Castellonense de Cultura, XXXIV, 24-58.

Alier, R. (1990). L'òpera a Barcelona: Orígens, desenvolupament i consolidació de l'òpera com a espectacle teatral a la Barcelona del segle XVIII. Barcelona: Institut d'Estudis Catalans.

Амат, X. (2014). Elisabet Cristina de Brunsvic: La reina dels catalans a Mataró: Juliol de 1708. Mataró: Ajuntament de Mataró; Barcelona: Abadia de Montserrat.

Anguera, P. (2008). L'Onze de Setembre, història de la Diada (1886-1938). Barcelona: Centre d'Història Contemporània de Catalunya / Publicacions de l'Abadia de Montserrat.

Ayats, J. (2009). «Les cançons dictades al segle XVII i principis del XVIII». Recerca Musicològica, XIX, 229-240.

Barceló Porcel, G. (2003). «El Carrasclet, història o llegenda». Estudis Prioratins, 3, $7-42$.

Barniol i Boixader, F. (2007). Francesc Macià i Ambert, Bac de Roda (1658-1713): Família i trajectòria d'un dirigent de la Guerra de Successió. Les Masies de Roda: Ajuntament de Les Masies de Roda.

BARó i Queralt, X. (2005). «La historiografia catalana en el segle del Barroc (15851709)» [tesi doctoral]. Dir. Fernando Sánchez Marcos. Departament d'Història Moderna de la UB.

- (2009). La toga, l'espasa i la mitra: Antologia de textos d'història i literatura catalanes del Barroc (1573-1709). Barcelona: Dux.

Batlle, J. B. (1924). Los goigs a Catalunya: Breus consideracions sobre son origen y sa influència en la poesia mística popular: Acompanyan aquesta obra cent facsímils reproduhits de goigs del segle XVII. Barcelona: L'Arxiu.

Bernardini, L. (2009). «Ferdinando Galli Bibiena alla corte di Barcellona e la scenografia per la Festa della Peschiera». Quaderns d'Itàlia, 14, 131-158.

Blasco, R. (1985). «La veu popular en la Guerra de Successió». La insolent sàtira antiga (assaig d'aproximació a la poesia valenciana de caire popular). Xàtiva: Ajuntament de Xàtiva.

Bonastre, F. (2009). «L'òpera Il più bel nome d'Antonio Caldara i la recepció del darrer barroc a Catalunya». Recerca Musicològica, XIX, 77-102.

Bonaventura I IVARs, M. (2010). «L'emblemàtica commemorativa: Un gènere que abandona els llibres per incorporar-se a la bullícia de l'espai públic i de les celebracions». A: Miralles, E. (ed.). Del Cincents al Setcents: Tres-cents anys de literatura catalana moderna. Bellcaire d'Empordà: Vitel·la, 401-437.

Borreguero Beltrán, C. (2003). «Imagen y propaganda de guerra en el conflicto sucesorio (1700-1713)». Manuscrits, 21, 95-132.

Bou, E. (2000). Diccionari 62 de la literatura catalana. Barcelona: Edicions 62.

Bover, J. M. (1868). Biblioteca de escritores baleares. Palma: Imprenta de P. J. Gelabert.

Bravo, I. (1986). L'escenografia catalana. Barcelona: Diputació de Barcelona.

Broch, A. (ed.) (2008). Diccionari de la literatura catalana. Barcelona: Enciclopèdia Catalana.

Brossa, J. (2001). Antologia de poemes de revolta. A cura de Glòria Bordons. Barcelona: Edicions 62.

Brown, K. (1988). «Textos poètics inèdits del barroc català exhumats en biblioteques nord-americanes». A: Rasico, P. D.; Wittlin, C. J. (ed.). Actes del Cinquè Col-loqui 
d'Estudis Catalans a Nord-Amèrica (Tampa - St. Augustine, 1987). Barcelona: Publicacions de l'Abadia de Montserrat, 163-200.

- (1989a). «Los juegos olímpicos en Barcelona, 1702/1703: un episodio de la historiografía literaria y militar de Cataluña». Diálogos Hispánicos de Amsterdam, 8: III, 903-913.

—(1989b). «Encara més sobre Serra i Postius». A: Badia i Margarit, A. M.; Camprubí, M. de (ed.). Actes del Vuitè Col-loqui Internacional de Llengua i Literatura Catalanes (Tolosa de Llenguadoc 12-17 de setembre de 1988), II. Barcelona: Publicacions de l'Abadia de Montserrat, 267-289.

—(1989-1990). «Antoni Peguera i Aimeric (1680/1681-1707): obres en català i en castellà». Boletín de la Real Academia de Buenas Letras de Barcelona, XLII, 29-80.

-(2008). Els Jocs Olímpics a Barcelona el 1703: Una lliçó per entendre la desfeta de l'Onze de Setembre del 1714. Barcelona: Institut de Cultura de Barcelona. Segons ha tingut l'amabilitat d'informar-me'n l'autor, la inèdita ponència que va presentar al XII Col-loqui de la North American Catalan Society, celebrat el 2007 a la Dalhousie University, va servir de base per a aquest estudi.

—(2011-2012 [2015]). «Nous versos d'Antoni de Peguera i Aimeric: el Poema armónico que se cantó, en aplauso de un natalicio». Butlletí de la Reial Acadèmia de Bones Lletres de Barcelona, LIII, 123-179.

Brown, K.; Martínez Alonso, J. M. (2014). «Textos manuscrits culturals de l'època moderna en llengua catalana existents en la col-lecció de la Hispanic Society of America». Catalan Review, XXVIII, 135-160.

Brown, K.; Melchor, V. de (1995). Vida i obra de Joan de Gualbes i Copons. Barcelona: Curial / Publicacions de l'Abadia de Montserrat.

Burguny i Castelló, A. (1997). Teatre i poesia. A cura de Ramon Díaz i Villalonga. Barcelona: Publicacions de l'Abadia de Montserrat.

Campabadal i Bertran, M. (2003-2004). El pensament i l'activitat literària del Setcents català, I-II. Barcelona: Universitat de Barcelona.

-(2006). La Reial Acadèmia de Bones Lletres de Barcelona en el segle XVIII: L'interès per la història, la llengua i la literatura catalanes. Barcelona: RABLB / Publicacions de l'Abadia de Montserrat.

- (2007). «Austriacisme i literatura a l'Acadèmia dels Desconfiats». A: Actes del Congrés l'Aposta Catalana a la Guerra de Successió (1705-1707): 3-5 novembre 2005. Barcelona: Generalitat de Catalunya / Museu d'Història de Catalunya, 217-231.

— (2008). «De l'èpica catalana setcentista». A: Miralles, E.; Malé, J. (ed.). Formes modernes de l'èpica (del segle XVI al segle XX). Santa Coloma de Queralt: Obrador Edèndum, 39-74.

- (2009). Diario del sitio y defensa de Barcelona (1713-1714) (pròleg d'A. Alcoberro i X. Camprubí). València: Tres i Quatre.

Campmany i Guillot, J. (1999). «La Guerra de Successió a Gavà i Eramprunyà (17001720)». Materials del Baix Llobregat, 4, 88-100.

Camprubí i Pla, X. (2010). «Premsa i impremta a Barcelona (1652-1714): l'estamper Rafael Figueró». Pedralbes, 30, 325-331.

- (2013). «L'impressor Rafael Figueró (1642-1726) i la premsa a la Catalunya del seu temps». [tesi doctoral]. Dir. A. Alcoberro i Pericay. Departament de Geografia i Història de la UB.

Carrera Pujal, J. (1951). La Barcelona del segle XVIII. Barcelona: Bosch, 1951.

Casademunt i Fiol, S. (2001). «La Capella Reial de Carles III a Barcelona. Nova documentació sobre la música a la ciutat durant la Guerra de Successió (1705-1713)». Revista Catalana de Musicologia, IV, 81-100. 
Castellví, F. de (1997-2002). Narraciones históricas, I-IV. A cura de Josep M. Mundet i Gifre i Josep M. Alsina Roca. Madrid: Fundación Francisco Elías de Tejada y Erasmo Pèrcopo.

Centre de Documentació i Museu de les Arts Escèniques de l'Institut del Teatre. «Guia del Tricentenari» (2014) <http://cdmae.cat/ca/s-xviii/1706-sitio-de-barcelona>. Tots els enllaços s'han revisat el 12-2-2016. Aquesta pàgina web ja no es localitza.

Colomer i Preses, I. (1981). «Les mosques i sant Narcís». Annals de l'Institut d'Estudis Gironins, 25, 2, 535-542.

Comas i Pujol, A. (1981). Història de la literatura catalana, IV. 2a ed. [1a. ed. 1964]. Barcelona: Ariel.

— (1985). «La consciència històrico-política en els poetes catalans del segle XVIII». A: íd. Estudis de literatura catalana. (Segles XVI- XVIII). Barcelona: UB / Curial, 142-160. Publicat en Problemes de llengua i literatures catalanes: Actes del II Col-loqui Internacional sobre el Català: Amsterdam 1970, Barcelona: Publicacions de l'Abadia de Montserrat, 1976, 275-295.

Constans, L. G. (1947). «Las moscas de san Narciso (un documento inédito)». Anales del Instituto de Estudios Gerundenses, II, 254-257.

Coroleu Lletget, A. (2006). «The siege of Barcelona of 1706 in three Latin texts». A: Verbeke, D.; Money, D.; Deneire, T. (ed.). Ramillies: A commemoration in prose and verse of the 300th anniversary of the battle of Ramillies, 1706. Cambridge: Bringfield's Head Press, 91-98.

Coroleu Lletget, A.; Paredes Baulida, M. (2010). «Épica llatina i Guerra de Successió». A: Borrell Vidal, E.; Ferreres Pérez, L. (ed.). Artes ad hvmanitatem, II. Barcelona: SEEC, 245-336.

-(2014a). Barcelona atacada pels francesos. Martorell: Adesiara.

- (2014b). «Llatí i consciència política a la Catalunya setcentista». Caplletra, 57, 215-231.

Cortadellas, A. (1998). «Les Mosques de Girona: erudició i fantasia». Revista de Giro$n a, 190,44(500)-47(503)$.

Cortès, F. (2009). «Òperes a Barcelona a principis del segle XVIII: intercanvis i adaptacions». Revista Musicológica, XIX, 185-197.

Cuesta García de Leonardo, M. J. (2009). «Felipe V y Carlos III en la Guerra de Sucesión: la construcción de sus imágenes desde las decoraciones efímeras». A: Congreso Internacional Imagen y Apariencia: Noviembre 19, 2008 - noviembre 21, $2008<\mathrm{http}: / /$ congresos.um.es/imagenyapariencia/imagenyapariencia2008/paper/viewFile/1991/195>.

— (2011). «Emblemática militante: El uso del emblema en la decoración efímera para tiempos de guerra». Zafra Molina, R.; Azanza, J. J. (coord.). Emblemática trascendente: Hermenéutica de la imagen, iconología del texto, Pamplona: Universidad de Navarra, 251-261.

Duran, E. (dir.) (2011). Manuscrits catalans de l'Edat Moderna. <http://mcem.iec.cat>.

Escartí, V. J. (1991). «Les "profecies” de fra Joan Escuder: Notes a l'edició de les versions dels segle XVI i XVIII». Almaig, VII, 74-80.

—(2007). El Diario (1700-1715) de Josep Vicent Ortí i Major. València: Fundació Bancaixa.

— (2013). «Carles Gassulla d'Ursino (1674-1745) i el Pensil celeste de flores: A propòsit d'un autor quasi desconegut». eHumanista: Journal of Iberian Studies. III, 143-229.

Escobedo, J. (1995). «Poesía catalana y pliegos de cordel». Anthropos, 166-167, 139-145. - (1996). «La colección de "Folletos Bonsoms" de la Biblioteca de Catalunya». A: GarCía de Enterría, M. C.; Ettinhausen, H.; Infantes, V.; Redondo, A. (ed.). Las 
relaciones de sucesos en España (1500-1750): Actas del Primer Coloquio Internacional (Alcalá de Henares, 8, 9 y 10 de junio de 1995). París: Publications de la Sorbonne; Alcalá de Henares: Servicio de Publicaciones de la Universidad, 103-109.

- (2009). «Documentació impresa en l'època de la Guerra de Successió». Recerca Musicològica, XIX, 45-75.

Escobedo, J. (ed.); Rossell, A. (dir.) (2013). Cançons i romanços populars catalans de la Guerra de Successió (s. XVIII) [CD]. La Garriga: Albert Moraleda.

Escofet, P. (1923-1927[1932]). «Cuatro piezas de poesía política en títulos de comedias, existentes en la Biblioteca de Cataluña». Butlletí de la Biblioteca de Catalunya, VII, 155-212.

Erill i Pinyot, G. (2014). «El clergat a Catalunya durant la Guerra de Successió». Arraona, 34, 116-147.

Étienvre, J. P. (1981-1982). «Campaña de Marte y mesa de la Fortuna (La guerra de Sucesión de España a través de un juego de rentoy)». Boletín de la Real Academia de Buenas Letras de Barcelona, 38, 225-269.

- (1990). Márgenes literarios del juego: Una poética del naipe: Siglos XVI- XVIII. Londres: Tamesis Books.

EurA, A. (2002). Obra poètica i altres textos. A cura de P. Valsalobre; pr. d'A. Rossich. Barcelona: Fundació Pere Coromines.

Feliu de la Peña y Farell, N. (1709). Anales de Cataluña y epílogo breve de los progresos y famosos hechos de la nación catalana, I-III. Barcelona: Juan Pablo Martí.

Feliu i Torrent, F. (2011). «La llengua literària». A: Garcia Espuche, A. (coord.). Llengua i literatura: Barcelona 1700. Barcelona: Barcino / Ajuntament de Barcelona, 207-243.

FERnÁndez, R. (2012). «Absolutismo borbónico y teatro en la España del setecientos». El teatro en la España del siglo xvIII: Homenaje a Josep Maria Sala Valldaura. Lleida: UdG, 45-57.

Foguet, F. (2015). «Nòtul-les sobre "Comedia famosa del sitio de Barcelona y fuga del duque de Anjou”, de Josep Ribes (1706)»<http://ddd.uab.cat/record/130654>.

Fontcuberta i Famadas, J. (2005). Molière a Catalunya: La recepció del dramaturg al primer terç del segle Xx. Pròleg d'E. Gallén. Barcelona: Publicacions de l'Abadia de Montserrat.

Fradera, J. M. (1993). Passat i identitat: la Guerra de Successió en la política i la literatura del segle XIX. Barcelona: Ajuntament de Barcelona.

Furió VAyÀ, J. M. (2001). «Els poemes valencians de Josep Vicent Ortí: Estudi i edició». Caplletra, 31, 115-150.

Gabancho, P. (2014). Les dones del 1714. Barcelona: Columna.

Galindo Blasco, E. (1994). «El penúltimo homenaje a la Casa de Austria en Barcelona: Los emblemas en las exequias del emperador José I». A: Sebastián López, S. (ed.). Actas del I Simposio Internacional de Emlemática: Teruel, 1 y 2 de octubre de 1991. Terol: Instituto de Estudios Turolenses.

Galindo López, E.; Medarde Sagrera, M. ([2014]). «Joan de Gualbes i Gaudí: Bellesguard i els Desconfiats de la Guerra de Successió». <http://bellesguardgaudi.com/sites/ default/files/archivos/Joan_de_Gualbes_i_Gaudi.pdf>.

García Cárcel, R. (ed.) (2002). De los elogios de Felipe V. Madrid: Centro de Estudios Políticos y Constitucionales.

Garcia Espuche, A. (coord.) (2009a). Dansa i música: Barcelona 1700. Barcelona: Ajuntament de Barcelona. 
—(2009b). Jocs, triquets i jugadors: Barcelona 1700. Barcelona: Ajuntament de Barcelona. - (2014). Una societat assetjada: Barcelona 1713-1714. Barcelona: Empúries.

Garcia Quera, O. (2013). Barcelona 1706-1714: Dietari d'un adroguer. Barcelona: Ajuntament de Barcelona.

Garcías Estelrich, D. (1998). Teatro y sociedad en la Mallorca del siglo XVIII. Palma: Lleonard Muntaner.

- (2003). Coronación de Nuestro Católico Monarca Carlos Tercero. A: Mas I Vives, J. (dir.). Diccionari del teatre a les Illes Balears, I. Palma: Lleonard Muntaner; Barcelona: Publicacions de l'Abadia de Montserrat, 201.

- (2005). Historia del teatro en Mallorca: Del Barroco al Romanticismo (1600-1834). Palma: Lleonard Muntaner.

Gifre, P. (2012). «Les consequiències demogràfiques i econòmiques de la guerra». A: García Espuche, A. (coord.). Política, economia i guerra: Barcelona 1700. Barcelona: Ajuntament de Barcelona, 246-255.

- (2013). «La guerra dels papers». A: Alcoberro, A. (coord.) (2013). 1714: La Guerra de Successió. 2a ed. [es va editar el 2006 per la mateixa editorial amb el títol de Catalunya durant la Guerra de Successió], II. Barcelona: Ara Llibres, 52-59.

Gilard, C. (2000). «Le roi et l'intrus: Héroïsme et propagande politique dans le cordel narratif de la Guerre de Succession: 1700-1714» [tesi doctoral]. Dir. M. Torrione. Departament d'Études Hispaniques de l'Université de Toulouse - Le Mirail.

- (2005). «Santos y héroes en la propaganda borbónica de la coronación de Felipe V a la Guerra de Sucesión». A: Vitse, M. (ed.). Homenaje a Henri Guerreiro: La hagiografía entre historia y literatura en la España de la Edad Media y del Siglo de Oro. Madrid: Iberoamericana; Frankfurt am Main: Vervuert, 653-667.

Girbal, E. C. (1887). «Otro poeta catalán desconocido (Lo Rector de Garriguella)». Revista de Gerona, [10]-11, 289-293 i 340-350.

González Toran, X. (2013). «BCN 1713. Literatura». Time Out Barcelona, 282, 18.

Grilli, G. (1985). «Poesia artificiosa e metametrica nella letteratura catalana». Annali del Istituto Universitario Orientale: Sezione Romanza, 27, 293-355.

IbáÑEZ JoFre, X. (1982). «Els romanços i els plecs austriacistes en la Guerra de Successió» [tesi de llicenciatura]. Dir. Pere Molas i Ribalta. Facultat de Geografia i Història de la UB.

— (1983). «Els romanços i els plecs austriacistes en la Guerra de Successió». Pedralbes, 3, 315-320.

Iglésies, J. (1954). «Preliminars». A: Vilà, C. Amor al Rey y a la pàtria, vinguda de Pere Juan Barceló dit Carrasclet, en Reus: 1713-1749. Reus: Asociación de Estudios Reusenses.

León SAnZ, V. (2007a). «"Abandono de patria y hacienda”. El exilio austriacista valenciano». Revista de Historia Moderna, 25, 235-255.

— (2007b). «Un exili oblidat: els valencians austriacistes». A: Cervera Torrejón, J. L.; Gavara Prior, J.; Mira González, E. La batalla d'Almansa, 1707: III centenari. València: Generalitat Valenciana, 201-219 i, en versió anglesa, 359-369.

Lolo Herranz, B. (2009). «El teatro con música en la corte de Felipe V durante la Guerra de Sucesión, entre 1703-1707». Recerca Musicològica, XIX, 159-184.

López Alemany, I.; Varey, J. E. (2006). El teatro palaciego en Madrid: 1707-1724. Estudio y documentos. Woodbridge: Tamesis.

López Poza, S. (ed.) (1994). Literatura emblemática hispánica: Actas del I Simposio Internacional. La Corunya: Universidade da Coruña.

Llombart, C. (1879). Los fills de la morta-viva: Apunts bio-bibliogràfichs pera la historia del renaixement lliterari llemosí. València: Emili Pasqual. 
Lluch, E. (ed.) (2005). Escrits polítics del segle XVII: Tom III: Via fora als adormits. Barcelona: Institut Universitari d'Història Jaume Vicens i Vives; Vic: Eumo.

Manual de novells ardits vulgarment apellat Dietari del Antich Consell Barceloní (1975). Barcelona: Ajuntament de Barcelona.

MARTí, J. (2014). «Els goigs, un gènere de resistència». 440 Clàssica \& Jazz, 17, 42-43.

Martí Mestre, J. (2013). «Poemes burlescos, satírics, laudatoris i de disbarats en un manuscrit valencià del segle XVIII». eHumanista: Journal of Iberian Studies. III, 230-257.

Martí i Pol, M. (1989). Obra poètica, I: 1948-1971. Barcelona: Edicions 62.

Massanés, C.; Serra, E. (2014). «Les dones del 1714». Sàpiens, 138, 58-59.

Massip, F. (2012). «El teatre català entre la Il-lustració i el Romanticisme». A: SALORD, J. (coord.). Vicenç Albertí i el teatre entre la Il-lustració i el Romanticisme, I. Barcelona: Publicacions de l'Abadia de Montserrat, 11-30.

Merchán, J. C. (2006). La obra literaria de Carlos de la Rica. León: Universidad de León.

Mínguez, V. (1997). Emblemática y cultura simbólica en la Valencia barroca: jeroglíficos, enigmas, divisas y laberintos. València: Alfons el Magnànim.

Miquel, F. A. (1961). «Un profesor eximio de Santes Creus en el siglo Xvir: Fray Pablo Miracle». Santes Creus: Boletín del Archivo Bibliográfico, II, 13, 121-130.

Miralpeix i Vilamala, F. (2014). Antoni Viladomat i Manalt: 1678-1755: Vida i obra. Girona: Museu d'Art de Girona.

Molas Ribalta, P. (1988). «Sàtira política a València el 1735». Homenatge al Doctor Sebastià García Martínez, II. València: Conselleria de Cultura, Educació i Ciència de la Generalitat Valenciana / UV, 313-326.

Montagut, M. R. (2004). «Música y fiesta barroca: celebraciones en Tortosa en honor de Felipe V (1701)». Anuario Musical, 59, 85-114.

Mora, R. (2012). «Els document impresos sobre la batalla d'Almansa, una mostra de propaganda historiogràfica en el context de la Guerra de Successió». A: EscARTí, Vicent J.; Estrela, E. Josep Marco i la Guerra de Successió: Actes de les VII Jornades d'Estudi: Algemesí, 2-4 de maig de 2007. Algemesí: Ajuntament d'Algemesí, 137-191.

Morales y Marín, J. L. (2000). «La escenografía durante el reinado de Felipe V». A: ToRRIONE, Margarita (ed.) España festejante: El siglo XVIII. Málaga: Diputación, 287-293.

Nash, M. (2000). Gènere, identitat urbana i participació ciutadana. Barcelona: Institut de Cultura.

NúÑez LuQue, M. T. (1988). «La prensa periódica de Barcelona en el siglo XVIII: Prensa erudita, gacetas y pronósticos». Manuscrits, 7, 241-261.

[Oliver, J.] Quart, P. (1999). Obra poètica. A cura d'Helena Mesalles. Barcelona: Proa.

11 Setembre 1714 (2005-2014). «Literatura i premsa». <http://www.11setembre1714.org/ Literatura4.html>.

PAdRosa GoRgot, I. (coord.) (s. a.). Bibliografia interdisciplinària de l'Empordà. <http:// www.roger.es/bibliografia/detall.php?pagina=9490\&pagLlista $=633>$.

Palmada, G.; Vila, P. (2013). «La festa austriacista de Banyoles de l'any 1710». Annals de l'Institut d'Estudis Gironins, LIV, 429-452.

Pascual Ramos, E. (2009-2010). «Recreació literària d'un episodi de la guerra de Successió a Mallorca: la forja d'un heroi». Estudis Baleàrics, 96-97, 193-206.

Pérez Aparicio, C. (2008). Canvi dinàstic i Guerra de Successió: La fi del Regne de València. València: 3 i 4.

- (2012). «Catalunya i València durant la Guerra de Successió. "La comuna empresa de la llibertat"». Manuscrits, 30, 77-97. 
Pérez Picazo, M. T. (1966). La publicística catalana en la Guerra de Sucesión, I-II. Madrid: CSIC.

Pérez SAmper, M. À. (1989). «Les festes reials a la Catalunya del Barroc». A: Rossich, A.; RAfAnell, A. (ed.). El barroc català: Actes de les jornades celebrades a Girona els dies 17, 18 i 19 de desembre 1987. Barcelona: Quaderns Crema, 345-377.

- (2000). «Felipe V en Barcelona: un futuro sin futuro». Cuadernos Dieciochistas, 1, 57-106.

Pérez Treviño, O. (2014). «L'arribada del món de l'òpera a Catalunya». 440 Clàssica \& Jazz, 17, 29-35.

Pladevall i Font, A. (1996). Francesc Macià i Ambert, «Bac de Roda», heroi de la Guerra de Successió. Barcelona: Rafael Dalmau.

Porta i Bergadì, A. (1984). La victòria catalana de 1705. Barcelona: Pòrtic.

Pujol, E. (ed.) (2014). Antologia de memòries i dietaris personals catalans sobre la Guerra de Successió. Barcelona: IEC.

Pujol, J. (2014). «"Venid mortales”. Músiques gironines de la Guerra de Successió». A: Pujadó, J. (coord.). «300 anys després. La Guerra de Successió». Revista de Girona, 286, $72-76$.

Querol, E. (2001). «"La consolidació corporal i temporal del poble”: Pervivència del teatre a la ciutat de Tortosa en els segles XVI-XVIII». A: Rossich, A. (coord.). El teatre català dels orígens al segle XVIII. Kassel: Reichenberger, 293-311.

— (2011). «Poetes i militars al Maestrat i els Ports a la Guerra de Successió». Boletín de la Sociedad Castellonense de Cultura, 87, 489-504.

Revilla, F. (1983). «Las adventencias políticas de Barcelona a Felipe V en las decoraciones efímeras de su entrada triunfal». Boletín del Seminario de Estudios de Arte y Arqueología, 49, 397-408.

Ribera i Bergós, J. (1985). «L'escenografia a Barcelona del 1700 al 1724» [tesi de 1licenciatura]. Dir. Santiago Alcolea i Gil. Departament d'Història de l'Art de la UB.

— (1987). «Ferdinando Galli Bibiena a la cort barcelonina de l'arxiduc Carles». Serra d'Or, 336, 61(733)-65(737).

Rica, C. de la (1993). Poesia (1959-1989). Barcelona: Anthropos.

Riera Fortiana, E. (1989). «Les festes celebrades a Catalunya durant el viatge i el casament de Felip V (1701-1702)». A: Rossich, A.; Rafanell, A. (ed.). El barroc català, 395-410.

— (1993). «Les institucions catalanes i Felip V durant la seva estada a Catalunya (17011702)». Pedralbes, 13: 2, 487-494.

Riera [Viader], S. (2013). Onze setembre: Història de la commemoració de la Diada a Barcelona. Barcelona: Efadós.

Roca i Ricart, R. (2012). «La Guerra de Successió i la Renaixença valenciana». A: Escartí, V.; Estrela, J. E. (ed.). Josep Marco i la Guerra de Successió: Actes de les VII Jornades d'Estudi: Algemesí, 2-4 de maig de 2007. Algemesí: Ajuntament d'Algemesí, 237-264.

Rodríguez de LA Flor, Fernando (1987). «Emblemática política en torno al rey Felipe V». Salamanca: Revista Provincial de Estudios, 24-25, 39-64.

RodrígueZ-SÁnchez de León, M. J. (2000). «La Guerra de Sucesión Española en los pliegos poéticos de la Biblioteca Universitaria de Salamanca». Cuadernos Diciochistas, 1, 185-208.

Roig, J. M. (2014). «L'Onze de Setembre com a símbol nacional. De la memòria immediata als nostres dies». A: Alcoberro, A. (dir.). Catalunya 1714-2014: La pervivència de la nació. Barcelona: Generalitat de Catalunya / Ara Llibres, 358-399. 
Ros, F. (1965). Antología poética de la lengua catalana (puesta en versos castellanos). Madrid: Editora Nacional.

Rossich, A. (1983). «La codolada, una forma mètrica catalana». JorbA, Manuel (ed.). Estudis de llengua i literatura catalanes oferts a R. Aramon i Serra en el seu setanta aniversari. Barcelona: Curial, 473-488.

— (1999). «La cultura literària gironina a l'època de Baldiri Reixach». Revista de Girona, 192, 51-54.

- (2001). «La mort de Francesc Fontanella: a propòsit d'una falsa atribució». Revue des Études Catalanes, 4, 87-100.

- (2010). «La fortuna literària i crítica de Francesc Vicenç Garcia». A: Miralles, E. (ed.). Del Cincents al Setcents: Tres-cents anys de literatura catalana moderna. Bellcaire d'Empordà: Vitel·la

Rossich, A.; CoRnellà, J. (2014). El plurilingüisme en la literatura catalana: Retòrica, versemblança, diglòssia. Bellcaire d'Empordà: Vitel-la.

Rossich, A.; Valsalobre, P. (2006). Poesia catalana del barroc: Antologia. Bellcaire d'Empordà: Vitel·la.

Roviró i Alemany, X.; Aiats i abeyà, J.; Girbau i Tàpies, V.; Roviró i Alemany, I. (2004). Història i memòria: Cançons populars de la història de Catalunya. Sant Vicenç de Castellet: Farell.

Rubió i Balaguer, J. (1985-1986). Història de la literatura catalana, III. Barcelona: Departament de Cultura de la Generalitat de Catalunya / Publicacions de l'Abadia de Montserrat. Traducció de la seva aportació a DíAz-PlAJA, G. (dir.) (1956-1958). Historia general de las literaturas hispánicas, IV/1 i V. Barcelona: Vergara.

Ruiz i Calonja, J. (1954). Història de la literatura catalana. Barcelona: Teide.

Sala Valldaura, J. M. (2007). Teatre burlesc català del segle XVIII. Barcelona: Barcino, 2007. SÁnchez Piñol, A. (2012). Victus: Barcelona 1714. Barcelona: La Campana.

SANChis GuARner, M. (1985). La llengua dels valencians. 10a ed. [1a. ed. 1933]. València: 3 i 4.

-(2001) Els valencians i la llengua autòctona durant els segles XVI, XVII i XVIII. [1a. ed. 1963]. València: Universitat de València.

Sansano, G. (ed.) (2001). «El Col-loqui per a la festa de Nostra Senyora de la Esperanza en lo any 1730..., un exemple de contrafactum: Estudi i edició». A: Rossich, Albert (coord.). El teatre català dels orígens al segle XVIII, 371-389.

Serra, E. (1984). «Els Gualbes ciutadans de Barcelona: de la fallida bancària del segle XV a l'enllaç nobiliari del segle XvII». Primer Congrés d'Història Moderna de Catalunya. Barcelona: Departament d'Història Moderna de la UB, 479-494.

Serrà Campins, A. (1987). El teatre burlesc mallorquí, 1701-1850. Barcelona: Curial Edicions Catalanes / Publicacions de l'Abadia de Montserrat.

Simó, C. (1981). «Notes sobre l'Arte de poesía castellana, de Tomàs Barceló». Affar, 1 (1981), 129-133.

Simó, G. (1979). «Pronòstics mallorquins del segle XVIII». Randa, 8, 49-124.

Simon i TARrés, A. (2013). «La Guerra de la Successió en la Renaixença: La recuperació de la memòria històrica». A: Alcoberro, A. (dir.). La Guerra de Successió dia a dia: 1760-1900. Barcelona: Sàpiens, VI, 58-75, i Alcoberro, A. (coord.). 1714: La Guerra de Successió. 2a ed., III, 168-183.

SoberanAs, A. J. (1973). «Apunts per a una biografia de Josep Romaguera». A: In memoriam Carles Riba (1959-1969). Barcelona: UB / Ariel, 447-456.

Socias, I. (2013). «Els Galli Bibiena a Barcelona». A: Alcoberro, A. (coord.) (2013). 1714: La Guerra de Successió, I. 2a ed. Barcelona: Ara Llibres, 232-233. 
Sommer-Mathis, A. (2007). «Música y teatro en las cortes de Madrid, Barcelona y Viena durante el conflicto dinástico Habsburgo-Borbon. Pretensiones políticas y teatro cortesano». A: Álvarez-Ossorio, A.; García García, B. J.; León, V. (ed.). La pérdida de Europa: La guerra de Sucesión por la Monarquía de España. Madrid: Fundación Carlos de Amberes, 181-198.

Sunyer, M. (2001). «La Guerra de Successió a la poesia catalana romàntica». Símbols $i$ mites a l'Espanya contemporània. Reus: Centre de Lectura, 163-189.

-(2006). Els mites nacionals catalans. Vic: Eumo, 2006.

— (2014a). «Textos» de «El 1714 a la literatura catalana dels segles XIX i XX». A: Literatura i història: IX Jornada sobre Literatura i Ensenyament. Lleida: Càtedra Màrius Torres <http://www.catedramariustorres.udl.cat/activitats/jornades/jorn_12t1.pdf >.

— (2014b). «La Guerra de Successió en la literatura catalana». Revista de Catalunya, 287, 74-84.

SuRÉdA, F. (2002). «Los entretelones del poder en el teatro de Valencia durante la Guerra de Sucesión (1705-1707)». A: Meyran, D.; Ortiz, A.; SurÉda, F. Théâtre et pouvoir: Actes du IVe colloque international sur les théâtre hispanique, hipano-américain et mexicain en France: 8, 9 et 10 octobre 1998, Université de Perpignan. Perpinyà: CRILAUP / Presses Universitaires de Perpignan, 29-33.

- (2004). Le Théâtre dans la société valencienne du XVIIIe siècle. Perpinyà: Presses Universitaires de Perpignan.

Tagell, F. (1971). Relació de la mort de Climent XII i de l'elecció de Benet XIV (1740). A cura de Joan Mascaró. Barcelona: UB.

Tegell, F. (1989). Poema anafòric. A cura de Kenneth Brown. Barcelona: Curial / Publicacions de l'Abadia de Montserrat.

TORRAS I RibÉ, J. M. (2000). «La rereguarda catalana entre la darrera ofensiva aliada i el capgirament internacional (1710-1712)». Manuscrits, 18, 63-91.

- (2007). La Guerra de Successió i els setges de Barcelona (1697-1714). 2a ed. Barcelona: Rafael Dalmau.

Torrent, A. M. ([1967]). «Lo Desengany: Francesc Fontanella» [tesi de Llicenciatura]. Dir. A. Comas. Barcelona: [Facultat de Filosofia i Lletres de la UB].

— (1968). «Pròleg». A: Fontanella, F. Lo desengany. Barcelona: Edicions 62, 5-12.

Torrente, A. (2007). «Villancios de reyes: Propaganda sacromusical en Cataluña ante la sucesión a la Corona española (1700-1702)». A: Álvarez-Ossorio, Antonio; García García, Bernardo J.; León, Virginia (ed). La pérdida de Europa: La guerra de Sucesión por la Monarquía de España. Madrid: Fundación Carlos de Amberes, 199-246.

VAlsalobre, P. (2001-2002). «Agustí Eura i les muses catalanes a l'Acadèmia de Barcelona». Boletín de la Real Academia de Buenas Letras de Barcelona, XLVIII, 161-212.

— (2003) «El senyor de les mosques: Aspectes de l'evolució de la llegenda de les mosques de sant Narcís fins al segle XVII i relació amb el "patriotisme sacre" a la Catalunya moderna». Revista de Catalunya, 189, 67-100.

- (2004). «Mosques, sants i política a la Catalunya moderna: L'episodi del setge de 1653». Revista de Girona, 226, 63 (643) - 70 (650).

- (2015). «En els marges de la poesia fontanellana: els textos d'atribució dubtosa o falsa (una aproximació)», Revista de Cancioneros Impresos y Manuscritos, 4, 132-166.

Valsalobre, P.; Gratacós, J. (2001). Agustí Eura, O.S.A. (1684-1763), escritor y obispo: Un clásico de la poesía catalana de la Edad Moderna. Madrid: Revista Agustiniana.

Vela, N. (2014a). «Els goigs de la guerra de Successió». Catalunya Cristiana, XXXV, $1795,26$. 
—(2014b). Goigs de guerra i resistència [estudi i edició facsímil]. Barcelona: Amics dels Goigs.

Vila, P. (1992). «Dues mostres del teatre representat a Maó durant la dominació francesa». Revista de Menorca, LXXXIII, 1, 59-80.

Villalonga, A. M. (2009). «L'entremès Lo batlle i cort del borboll: Un testimoni inèdit del teatre català del segle XVIII». Els Marges, 88, 39-55.

ZabAla, A. (1966). «Representaciones teatrales en Valencia durante los años 1705, 1706 y 1707». Anales del Centro de Cultura Valenciana, II, 159-202.

ZaPATA FERnándeZ DE LA Hoz, T. (2000). «Alegorías, historias, fábulas y símbolos en los jeroglíficos de la entrada de Felipe V en la corte: Pervivencia de la iconografía de los Austrias». A: Torrione, M. (ed.). España festejante: El siglo XvIII. Málaga: Diputación, 405-422. 